\title{
Afferent Basis of Visual Response Properties in Area MT of the Macaque. I. Effects of Striate Cortex Removal
}

\author{
Hillary R. Rodman, Charles G. Gross, and Thomas D. Albright ${ }^{a}$ \\ Department of Psychology, Princeton University, Princeton, New Jersey 08544
}

\begin{abstract}
The middle temporal area (MT) of the macaque monkey is a region of extrastriate cortex involved in the analysis of visual motion. MT receives strong projections from striate cortex and from area V2, which is dependent on striate for visual responsiveness. Accordingly, the visual properties of MT neurons have been thought to reflect the further processing of its input from striate cortex. We examined the dependence of MT activity on pathways deriving from striate cortex by recording from MT neurons following removal of their striate input. Repeated recordings in area MT were made in $\mathbf{4}$ hemispheres of anesthetized macaques following either partial or total ablations of striate cortex. Cells in MT were tested for responsiveness, selectivity for direction of motion and direction tuning, and ocular dominance. Receptive fields were also plotted. In an additional animal, we recorded from MT neurons during reversible cooling of the central representation in striate cortex. We found that striate cortex removal or inactivation did not abolish the visual responsiveness of the majority of MT cells. Although the residual responses were generally much weaker than in the intact animal, direction selectivity and binocularity were still present. Moreover, receptive field size and overall topography appeared unaltered.
\end{abstract}

The middle temporal area (MT) of the macaque is a small, topographically organized cortical visual area buried in the posterior bank of the superior temporal sulcus (Zeki, 1974; Ungerleider and Mishkin, 1979; Gattass and Gross, 1981; Van Essen et al., 1981). The response properties of MT neurons have been extensively studied, and MT provides a particularly convincing example of functional specialization in primate extrastriate visual cortex. Most MT neurons are selective for both direction and speed of stimulus motion (Maunsell and Van Essen, 1983a, b; Albright, 1984; Rodman and Albright, 1987), and cells with similar preferred directions are organized into columns (Albright et al., 1984). Moreover, lesions of area MT disrupt psychophysical thresholds for detection and discrimination of visual motion (Newsome and Pare, 1986; Siegel and

\footnotetext{
Received June 13, 1988; revised Nov. 15, 1988; accepted Nov, 21, 1988.

We wish to thank L. Kuseryk and M. Hess for work on the histology and figures, M. Rosengarten for word processing, and an anonymous referee for suggestions on the manuscript. Dr. Peter Schiller of M.I.T. kindly loaned us the cooling plate and Peltier device. Support was provided by NIH Grant MH-19420, NSF Grant BNS-8200806, and an NSF Predoctoral Fellowship to H.R.

Correspondence should be addressed to Dr. Hillary R. Rodman, 1-E-15 Green Hall, Psychology Department, Princeton University, Princeton, NJ 08544

a Present address: The Salk Institute for Biological Studies, P.O. Box 85800 San Diego, CA 92138

Copyright (C) 1989 Society for Neuroscience $0270-6474 / 89 / 062033-18 \$ 02.00 / 0$
}

Andersen, 1986). Studies of the laminar pattern of reciprocal connections of MT with other cortical areas have shown that MT receives "ascending" inputs from striate cortex and extrastriate areas V2 and V3, "descending," or feedback, projections from areas MST, FST, and VIP, and a hierarchically intermediate projection from V4 and possibly V3A and PO (Cragg and Ainsworth, 1969; Ungerleider and Mishkin, 1979; Montero, 1980; Rockland and Pandya, 1981; Maunsell and Van Essen, 1983c; Ungerleider and Desimone, 1986). Subcortically, MT is reciprocally connected to the inferior and lateral pulvinar and sends projections to a number of additional regions, including the claustrum, pons, and superior colliculus (Glickstein et al., 1980; Maunsell and Van Essen, 1983c; Ungerleider et al., 1984).

Although area MT has been characterized in detail both physiologically and anatomically, very little attention has been given to the dependence of MT response properties on its inputs. Several lines of evidence suggest that striate cortex is likely to play an important or even exclusive role in the genesis of visual responses in MT. First, the greater part of MT's "ascending" input comes either directly from striate cortex or from the striaterecipient regions V2 and V3. Second, where it has been tested, other extrastriate visual cortical areas are known to lose their visual responsiveness following removal of striate input; such is the case for V2 (Schiller and Malpeli, 1977) and inferior temporal cortex (Rocha-Miranda et al., 1975). A third line of evidence comes from the antidromic experiments of Movshon and Newsome (1984), which suggested that the particular striatc cortex neurons that project to MT have receptive field organization and direction selectivity very similar to that of their MT targets.

However, there are also reasons for suspecting that regions other than the striate cortex might be capable of sustaining visual responsiveness in MT. For example, the superficial layers of the superior colliculus receive direct retinal input and project to the inferior and lateral pulvinar (Benevento and Fallon, 1975; Harting et al., 1980; Benevento and Standage, 1983), and thus MT might receive visual information over a tectopulvinar-MT pathway. The possibility of an important tectopulvinar input to MT is reinforced by the finding of a polysensory cortical region, the superior temporal polysensory area (STP), where some visual responsiveness survives striate cortex removal but is abolished by the addition of a superior colliculus lesion (Bruce et al., 1986).

In this investigation, we examined the dependence of visual responses in MT on the integrity of striate cortex. We recorded from neurons in area MT following lesions or reversible cooling of striate cortex. We found that while striate cortex removal or inactivation considerably weakens visual responses in MT, it does not completely abolish the responsiveness of most MT cells. Moreover, substantial direction selectivity remains in MT 
devoid of striatc input. This is the first cvidence of an exclusively visual cortical area in the primate that can operate partially in parallel with striate cortex.

For purposes of clarity, the body of this report is divided into 2 sections, one devoted to the methods and results of the striate lesion experiments and the other devoted to the methods and results of reversible cooling inactivation of striate cortex. A brief report of these findings has appeared in abstract form (Rodman et al., 1985).

\section{Effects of Striate Cortex Lesions}

\section{Materials and Methods}

Subjects. Three male Macaca fascicularis, weighing between 3.2 and 5.4 $\mathrm{kg}$ at the time of recording, were used in this portion of the study. The first animal, no. 542, received a partial unilateral ablation of striate cortex; the second, no. 555, received a partial bilateral striate cortex ablation; and the third, no. 561, received a total bilateral striate cortex ablation. Each monkey was allowed 5-6 weeks recovery after the striate cortex lesion and was subsequently recorded from in 8-12 sessions over a 4-6 week period.

Striate cortex lesions. Lesions were made under aseptic conditions while the animals were anesthetized with ketamine hydrochloride ( $\mathrm{Ke}-$ taset, $30 \mathrm{mg} / \mathrm{kg}$ ), supplemented with $50 \mathrm{mg}$ as needed. Atropine $(0.15$ $\mathrm{mg} / \mathrm{kg}$ ) was given $20 \mathrm{~min}$ prior to ketamine administration to reduce mucous secretions. Benzodiazepine (Valium, $2 \mathrm{mg}$ ) was given towards the end of surgery.

After removal of the overlying bone, partial lesions of striate cortex were made by aspiration of the exposed portion of striate on the dorsolateral surface of the occipital lobe. Additional cortex on the medial surface of the occipital lobe, up to the ascending and descending limbs of the calcarine sulcus (no. 555), or up to a few mm into the calcarine sulcus (no. 542), was also removed. The dural flap made to expose the cortex was then sutured, and the soft tissues and skin were sewn up around the edge of the wound.

The total striate cortex lesion was made using methods described previously (Mishkin, 1966; Bruce et al., 1986). A partial occipital lobectomy was made with an approximately coronal cut $8 \mathrm{~mm}$ posterior to the lunate sulcus. The striate cortex lying within the anterior portion of the calcarine sulcus and that remaining on the lateral and medial surfaces of the lobe was aspirated with the aid of an operating microscope. The wound was then closed in the same manner described for the partial lesions.

Preparation for recording. Recordings in MT were made through a 5-cm-diameter stainless steel chamber implanted over the midline at least a week prior to the striate cortex lesion. The recording chamber and cap and a stereotaxically positioned headbolt were mounted on the animal's skull with dental acrylic under aseptic conditions while the monkey received ketamine hydrochloride anesthesia, as described for the striate cortex lesions. Small stainless steel screws inserted tightly into the skull helped the dental acrylic to secure the hardware.

On the morning of a recording session, the animal was given an injection of atropine $(0.15 \mathrm{mg} / \mathrm{kg})$ followed by an initial restraining dose of ketamine $(10 \mathrm{mg} / \mathrm{kg})$. Next, the monkey was anesthetized with a $2: 1$ mixture of nitrous oxide and oxygen to which $2 \%$ halothane (Fluothane) was added. The monkey was then positioned in a stereotaxic apparatus by means of the headbolt and a special holder attached to the apparatus. The cap was removed from the recording chamber, and a small hole was drilled through the exposed bone. After this point, the halothane was discontinued and the animal was subsequently maintained under anesthesia with the $2: 1$ mixture of nitrous oxide and oxygen. Paralysis was induced with pancuronium bromide (Pavulon) in saline or dextroselactated Ringer's solution. The Pavulon was subsequently infused at a rate of $0.03 \mathrm{mg} / \mathrm{kg} / \mathrm{hr}$. Body temperature, heart rate, and end-tidal $\mathrm{CO}_{2}$ were monitored, and the respiration rate was adjusted to give an endtidal $\mathrm{CO}_{2}$ level of about $4 \%$. The pupils were dilated with cyclopentolate $\mathrm{HCl}$ (Cyclogyl, 1\%), and the corneas were covered with contact lenses selected by retinoscopy to focus the animal's eyes on a rear-projection tangent screen approximately $57 \mathrm{~cm}$ away.

Recording sessions lasted $13-17 \mathrm{hr}$ and were separated by a minimum of $2 \mathrm{~d}$. An hour before the end of each session, the Pavulon infusion was discontinucd. When the animal was brcathing normally on its own, it was returned to its home cage.
Recording procedure and visual stimulation. Extracellular potentials were recorded from single isolated neurons ("single units") or small groups of neurons ("multiunits") using varnish-coated tungsten microelectrodes (Fred Haer, Inc.) with exposed tips of approximately 10 $\mu \mathrm{m}$ and impedance of approximately 0.5-5 M . Electrodes were tilted forward $40^{\circ}$ from vertical in the parasagittal plane, passing dorsoanteriorly to ventroposteriorly. Neural activity was amplified and displayed on an oscilloscope. Spikes were judged to be arising from isolated neurons if they appeared constant in waveform and amplitude. Spikes thus recorded were converted into digital pulses and collected by a PDP 11/ $34 \mathrm{~A}$ computer. Both background activity and the output of the singleunit filter were also fed to speakers for audio monitoring.

Single and multiunits in MT were tested for visual responsiveness, direction selectivity, broadness of direction tuning, and ocular dominance using spots and bars of light from a hand-held projector. Judgments of directional characteristics and ocular dominance were made by the same observer throughout the experiments, and marginal responses were always verified with at least one other experimenter. Some single units were also tested with computer-controlled stimulus presentation and data collection.

Typically, upon entering MT, we would assess the overall sound of the cortex (spontaneous activity, burstiness) and the responsiveness and direction selectivity of the MT activity. We then proceeded to study individual cells or small groups of cells. First, the responsiveness of each single or multiunit was characterized as strong, weak, or absent. A variety of hand-held stimuli were tried in order to determine if any response could be evoked. These included moving and flashed spots, bars and squares of light, dark edges, and large stimuli such as pieces of cardboard. Second, if we could obtain a response, the receptive field (RF) was plotted. Third, we rated strength of direction selectivity and sharpness of direction tuning. Direction selectivity refers here to the relative strength of responses to motion in the preferred and anti-preferred directions, with a value of 0 indicating equivalent responses in both directions and a 5 indicating a response in the preferred direction and complete inhibition in the anti-preferred direction; a 2.5 , at the midpoint of the scale, was intended to indicate firing equivalent to background for stimulation with the anti-preferred direction of motion. Direction tuning, or sharpness of direction selectivity, reflects how selective the single or multiunit was for directions away from the optimal; a rating of 0 indicates no direction preference at all, and a rating of 5 indicates a response to only a very narrow range of directions of motion. Fourth, for the 2 animals with bilateral striate cortex lesions (nos. 555 and 561), we used the scheme of Hubel and Wiesel (1962) for ocular dominance to compare responses to stimulation of the contralateral and ipsilateral eyes.

We employed a number of strategies to insure that RFs were accurately plotted and, in the 2 cases with partial striate lesions, that responses were obtained from the presumptive RF and not from surrounding regions with intact striate input. First, we plotted the RF with the smallest stimulus available capable of evoking a reliable response from the cell (usually a short bar of light). Second, we attempted to check borders by determining the points at which the response stopped as the trailing edge of the stimulus passed out of the RF into more peripheral portions of the visual field. Finally, in cases of doubt, we used large pieces of opaque paper or cardboard to mask outlying portions of the visual field while we stimulated in the zone containing the putative RF.

Following the striate lesion, single MT units were considerably harder to isolate and hold for extended periods of time than they were in the normal animals (see Results), and many units exhibited bursty spontaneous activity and, to a lesser extent, variability of response. These phenomena, and our desire to sample cells throughout the representation of the visual field in MT, precluded the collection of a large sample of quantitative data. However, we did test a small number of well-isolated single units with the computer-controlled stimulus presentation and data-collection methods used in some of our previous MT studies (e.g., Albright, 1984; Rodman and Albright, 1987). Briefly, these methods were as follows. Stimuli were presented by an optical bench equipped with $X$-and $Y$-axis mirror galvanometers, a stepping-motor controlled rotation device, and an electronic shutter. The PDP 11/34A computer controlled the remote equipment and also collected and displayed data on-line in the form of peristimulus time histograms. Stimuli consisted of moving slits of light swept across the tangent screen in a path centered on the neuron's RF. For computer-controlled stimulus presentation, we used slits having dimensions and speed of movement estimated to be 
optimal with hand testing. Dimensions of the moving slit used for quantitative testing ranged from $0.5^{\circ}$ to $1^{\circ}$ in width and $3^{\circ}$ to $20^{\circ}$ in length; speeds used varied from $2 \% \mathrm{sec}$ to $64 \% \mathrm{sec}$. These ranges of stimulus parameters were similar to those employed in our earlier MT studies (Albright, 1984; Rodman and Albright, 1987). As is the case in normal MT, a slit of apparently optimal dimensions for a given cell was occasionally longer than the width of the cell's RF. Since we wanted to test cells in the striate lesion sample in the same way we had previously tested cells in normal MT, we used the optimal slit stimulus even if it did extend beyond a cell's RF borders. The moving slits were presented in 8 or 16 directions of motion with a constant angular deviation $\left(45^{\circ}\right.$ or $22.5^{\circ}$, respectively) separating one direction from the next. For the moving slit, orientation was always perpendicular to the direction of movement. For each cell studied in this manner, a test consisted of a series of 5-10 pseudorandomly interleaved presentations of each direction.

Histology. At the conclusion of experimentation, each animal was anesthetized with an overdose of intravenous sodium pentobarbitol and perfused through the heart with saline followed by $10 \%$ buffered formalin. The brains were then blocked in a stereotaxic apparatus and sectioned in the parasagittal plane with a freezing microtome. Sections were cut at $50 \mu \mathrm{m}$ and stained with cresyl violet or the Gallyas (1969) silver myelin stain.

Electrode penetrations and recording sites were reconstructed from serial sections stained with cresyl violet. Identification of tracks was aided by the locations of small electrolytic lesions ( $6 \mu \mathrm{A}, 20-30 \mathrm{sec}$ ) made at strategic points along some penetrations. The boundaries of area MT within the superior temporal sulcus were determined from myeloarchitectonic transitions seen in sections stained for fibers.

The extent of the visual field representation destroyed in striate cortex was estimated in 2 ways. First, the extent of striate cortex damage was evaluated using reconstructions of striate cortex topography from thc mapping studies of Gattass et al. (1981). Second, zones of degeneration in the lateral geniculate nucleus (LGN) were superimposed onto standardized maps of visual topography in the LGN based on the work of Malpeli and Baker (1975). The estimated error from examining the striate cortex was about $1^{\circ}$ within the central $10^{\circ}$ of the representation and increased to $5^{\circ}-10^{\circ}$ by about $40^{\circ}$ eccentricity. [Since one case (no. 555 ) had a lesion confined to the central $10^{\circ}$ and another (no. 561) was virtually total, error in estimating the more peripheral boundaries of the lesion applies to only one case (no. 542, unilateral lesion)]. The agreement of the estimates based on striate cortex and LGN damage was very good for each hemisphere.

\section{Results}

\section{Overview}

The results are based on a total of 269 MT recording sites (165 single and 104 multiunits) made along 55 penetrations in 4 hemispheres of the 3 animals with striate lesions. An additional 40 single units were studied with the same methods in 2 of the animals (nos. 542 and 555) prior to the striate cortex lesions. All of these recording sites were histologically determined to be within the myeloarchitectonic borders of MT; recordings made outside of MT are not included in the analysis. Single and multiunits were divided into 3 categories based on the locations of their RFs relative to the field defect resulting from the striate cortex lesion ("lesion zone"). The first category consisted of single and multiunits whose RFs were entirely or almost entirely within the lesion zone (RF area $80-100 \%$ within the field defect). The second category consisted of single and multiunits whose RFs fell partly (20-80\%) within the lesion zone. The third category consisted of single and multiunits with RFs entirely or almost entirely outside the lesion zone $(0-20 \%$ within the field defect). For purposes of categorization, the location and size of RFs fell partly (20-80\%) within the lesion zone. The third catcases were estimated on the basis of the fields plotted for the nearest responsive units on the same penetration (at least one responsive unit was found on each penetration). Since penetrations were made approximately normal to the cortical surface of MT, cells on a given penetration had very similar RFs, and estimations of RFs of unresponsive single and multiunits were thus made on the basis of RFs representing the same part of visual space. For the 37 unresponsive single and multiunits categorized in this fashion, the distance to the nearest responsive recording site ranged from 0.00 to $1.31 \mathrm{~mm}$, with a median separation of $0.18 \mathrm{~mm}$.

With one exception, the data obtained from each hemisphere were very similar, as described in subsequent portions of the Results, and have been pooled for discussion in this section. The exception was that in the unilaterally lesioned case (no. 542), a majority of single and multiunits with RFs along the vertical meridian or within the ipsilateral $5^{\circ}$ were found to give strong responses, including those with RFs within the field defect. By contrast, single and multiunits with RFs along the vertical meridian in the bilaterally lesioned animals were not significantly more responsive than those with RFs elsewhere within the lesion zone. Because interhemispheric connections between extrastriate areas preferentially connect the midline representation (Van Essen and Zeki, 1978), we suspected a commissural input to cells with RFs on or over the vertical meridian in the unilaterally lesioned case. Such inputs might possibly have derived from the contralateral (intact) striate cortex via the contralateral MT. Because of this possibility, data from these 56 recording sites are presented separately in the relevant portions of the Results.

The body of the Results is organized as follows. First, histological verification of the striate cortex lesions for each case will be presented. Second, after comments on recording quality, the effects of the striate cortex removal on the responsiveness of MT neurons will be described. Third, data will be presented on the directional characteristics and ocular dominance of MT neurons following the striate cortex lesions. Finally, we will consider RF size and topographic organization in MT following the striate cortex lesion.

\section{Histological findings}

Case no. 542 (partial unilateral lesion). Figure 1 shows representative sections through the cortex and LGN and the estimated field defect. Retrograde degeneration in the LGN indicated that the striate cortex lesion zone included the visual field representation to about $45^{\circ}$ along the horizontal meridian. Reconstruction of the lesion zone from the borders of the striate cortex lesion produced an estimate of the field defect that agreed well with the estimate derived from degeneration in the LGN. In total, the field defect extended about $10^{\circ}$ into both upper and lower fields at the midline and reached about $20^{\circ}$ into the upper and lower fields by about $20^{\circ}$ along the horizontal meridian. The most peripheral border of the defect was approximately $45^{\circ}$ along the horizontal meridian.

Case no. 555 (partial bilateral lesion, Fig. 2). The lesion was symmetrical across both hemispheres. All of the striate cortex on the dorsolateral surface was removed bilaterally, except for a narrow strip in each hemisphere lying at the dorsomedial edge of striate cortex along the lunate sulcus. In both hemispheres there was a slight invasion of the infragranular layers of striate cortex in the posterior-most portion of the calcarine sulcus, which is continuous with the posterior part of the medial edge of the dorsolateral striate cortex. Limited damage to V2 was present in both hemispheres on the dorsolateral surface, extending slightly onto the posterior banks of the lunate and inferior occipital sulci. Degeneration in each LGN was limited to 
the fovcal and parafoveal representation, consistent with the visible striate cortex damage. The estimated field defect was roughly circular, extending about $4^{\circ}$ into the upper field and $7^{\circ}$ along the horizontal meridian at maximum in both hemifields, about $6^{\circ}$ into the lower right hemifield, and about $8^{\circ}$ into the lower left hemifield.

Case no. 561 (total bilateral lesion, Fig. 3). No portion of striate cortex remained in either hemisphere except for a small tag of the anterior-most portion of the left calcarine sulcus, where far peripheral fields ( $>70^{\circ}$ eccentricity) are represented (Daniel and Whitteridge, 1961; Gattass et al., 1981). Dorsally, the lesion extended slightly onto the posterior bank of the lunate sulcus into V2. Ventral extrastriate damage was more severe in the right hemisphere, involving portions of V2, V3, and probably additional cortex anterior to V3 on the ventral surface. In the left hemisphere, some involvement of the same areas was present, but was less marked than in the right. Degeneration extended throughout the LGN in both hemispheres. The estimated field defect was thus total for at least the central $60^{\circ}$. In both hemispheres of this animal, the lesion extended into the white matter above the upper bank of the calcarine sulcus, in some places undercutting the floor of the lunate sulcus and coming within $3 \mathrm{~mm}$ of the posterior portion of MT in the superior temporal sulcus, where part of the lower field is represented (e.g., section $D$ in Fig. 3). Two penetrations placed into the posterior-most portion of MT in separate recording sessions yielded unusually poor transitions between the space in the fold of the superior temporal sulcus, the gray matter of MT, and the underlying white matter, as well as a very low spontaneous activity level in MT. No responses (and only 3 single units) were seen on these penetrations. On the other hand, all of the penetrations (a total of 10) made into the anterior half of MT had good transitions between the overlying sulcus, MT, and whitc matter and showed responsiveness and background activity consistent with recordings in MT after striate cortex removal in the other hemispheres. Many of the RFs recorded on these penetrations were within the upper visual field; thus, it is unlikely that the greater amount of extrastriate damage in this hemisphere explains the lack of responsiveness in the 2 posteriormost penetrations into the lower field representation, since the additional extrastriate involvement was predominantly in the ventral cortex, where upper fields are generally represented. Thus, we suspected that differential undercutting of subcortical projections to the anterior and posterior portions of MT was responsible for the presence and absence of activity, respectively, following the striate cortex lesion. Accordingly, we did not include the 3 units from the penetrations made into the posterior portion of MT in this animal in the data analysis.

\section{Overall recording quality}

Neural activity in normal MT cortex has a distinctive quality; visual responses are brisk and strong, and the spontaneous activity of most of its neurons does not tend to be bursty or highly variable under the conditions of anesthesia used in these experiments. By contrast, within the portion of MT visuotopically correspondent with the striate cortex lesion, responses of both single and multiunits were often weak, as detailed below, and RFs were more difficult to plot than in normal MT. Moreover, the cortex was frequently "injured" sounding (bursty or rhythmic background activity with single units firing trains of spikes). Single units were frequently difficult to isolate, and they tended to exhibit variable, bursty spontaneous activity. These phenom- no. 542
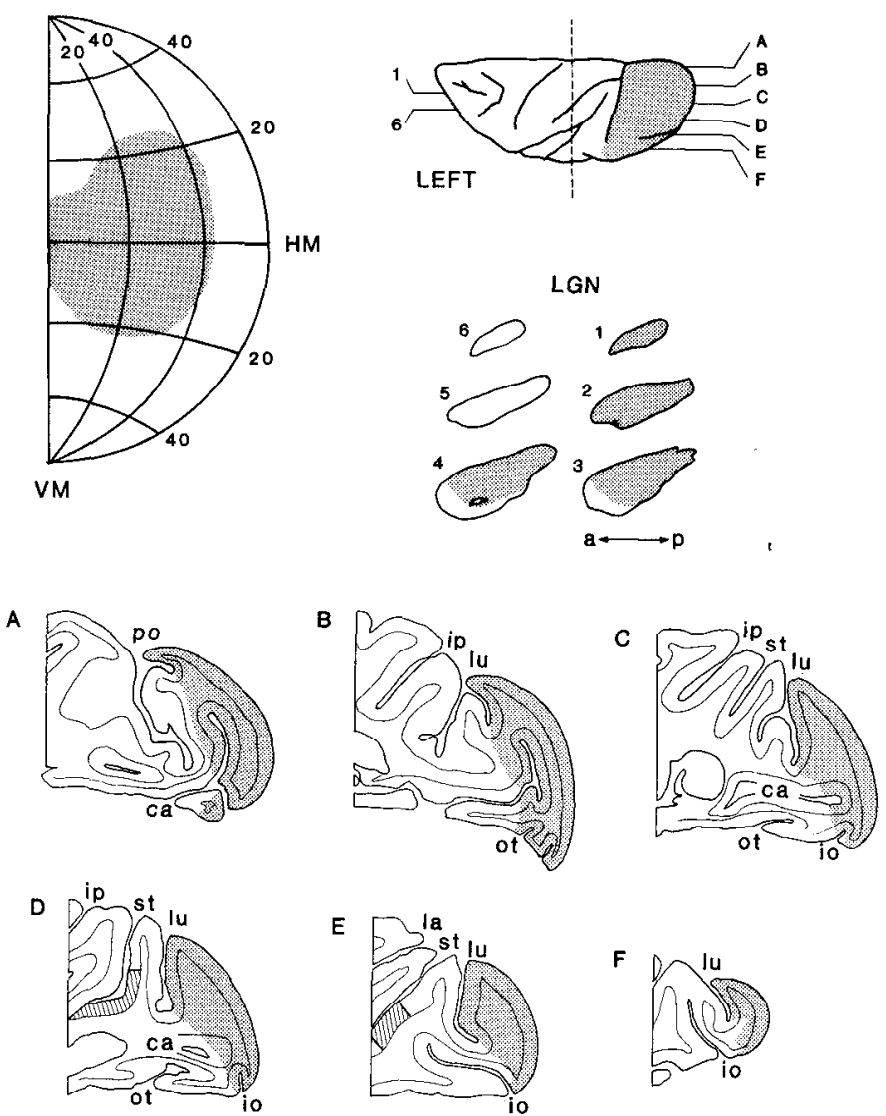

Figure 1. Reconstruction of striate cortex damage in case no. 542 (partial unilateral lesion). Right: Top, Dorsal view of left (lesioned) hemisphere, with missing or damaged tissue indicated by shading. Bottom, Parasagittal sections taken from levels shown on the dorsal view; anterior portion of each section has been cut off. Area MT is indicated by hatching. Right: Middle, Parasagittal sections through lateral geniculate nucleus $(L G N)$. Zones of retrograde degeneration are shown by shading. Left: Top, Map of visual field illustrating the estimated field defect ("lesion zone") resulting from the striate cortex lesion. Abbreviations: $a$, anterior; $p$, posterior; $c a$, calcarine sulcus; $i o$, inferior occipital sulcus; $i p$, intraparietal sulcus; $l a$, lateral sulcus; $l u$, lunate sulcus; $o t$, occipitotemporal sulcus; $p o$, parieto-occipital sulcus; st, superior temporal sulcus; $H M$, horizontal meridian; $V M$, vertical meridian.

ena were virtually absent outside the lesion zone and were rarer in the representation of the vertical meridian in the unilaterally lesioned case (see below).

\section{Responsiveness}

Figure 4 shows the incidence of responses classified as strong, weak, or absent for 213 MT recording sites in the 3 RF categories. (Data for single and multiunits with midline RFs in the unilateral case are described separately below.) Data from 40 single units in normal MT are also shown.

Following the striate cortex lesion, the majority $(66 \%)$ of single and multiunits with RFs within the lesion zone were still responsive, although only a few (5\%) gave responses classified as strong. In contrast, the majority of single and multiunits with RFs entirely outside the lesion zone gave strong responses, although the incidence of strong responses was somewhat less than in normal MT. The distribution of strong, weak, and no responses for single and multiunits with RFs only partly within 
RIGHT

A

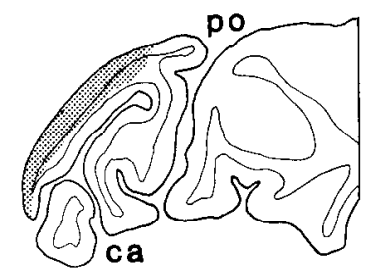

B
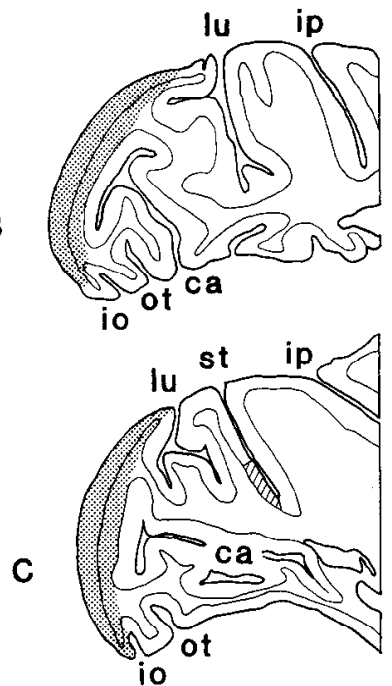

D
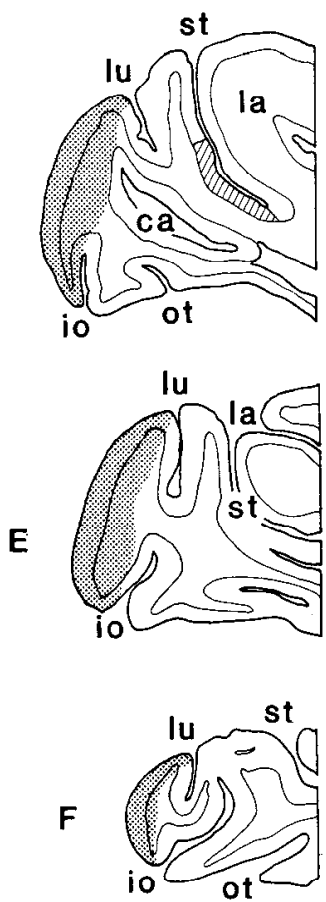

no. 555
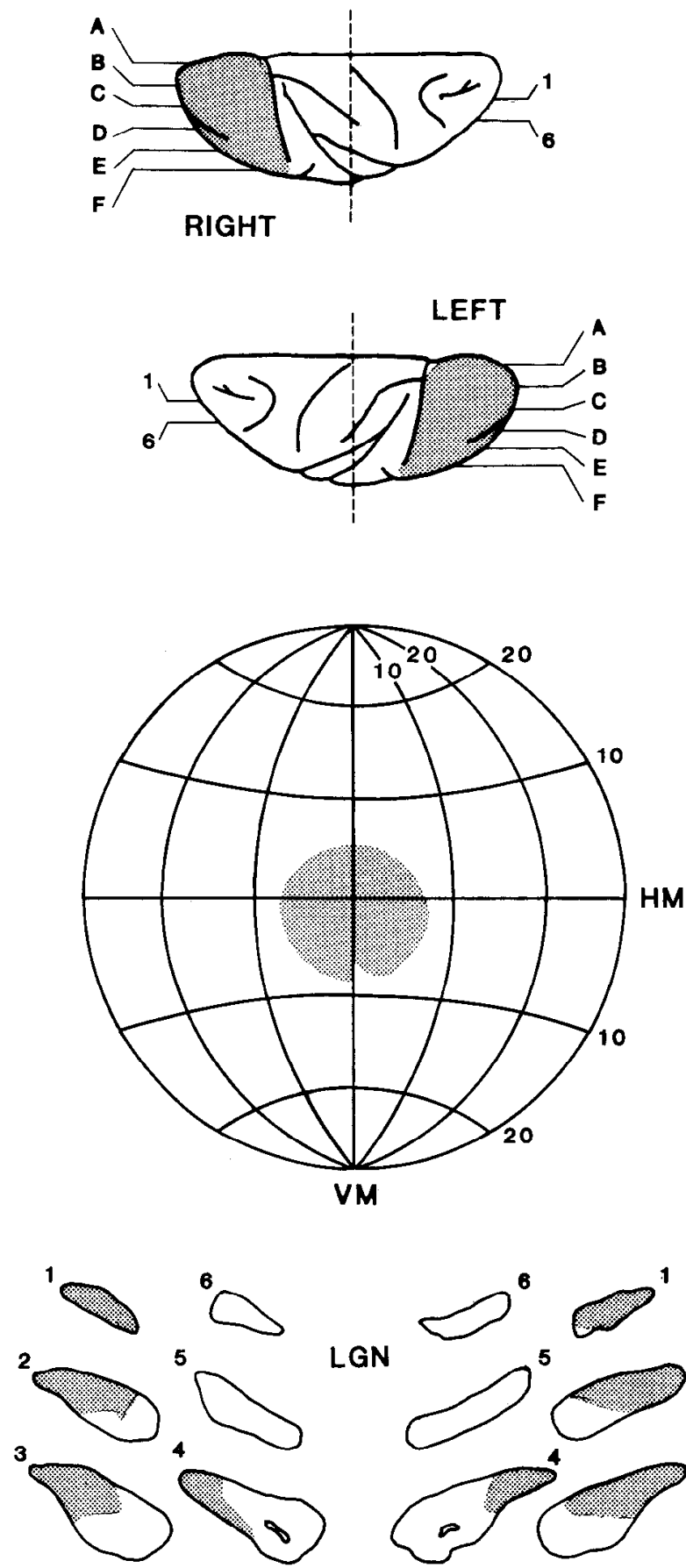
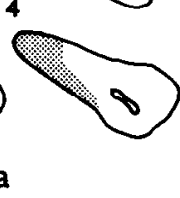

$\mathrm{p} \longrightarrow \mathrm{a}$

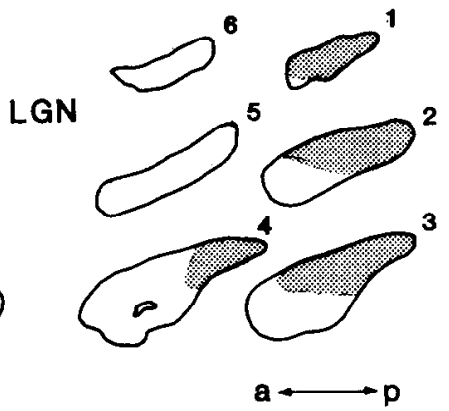

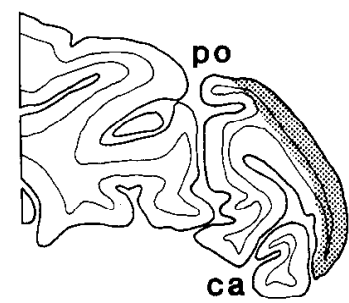

A

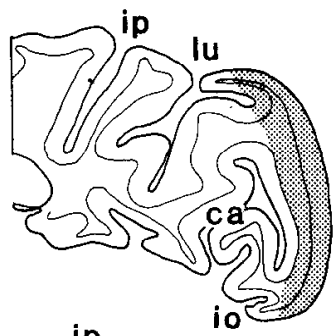

B
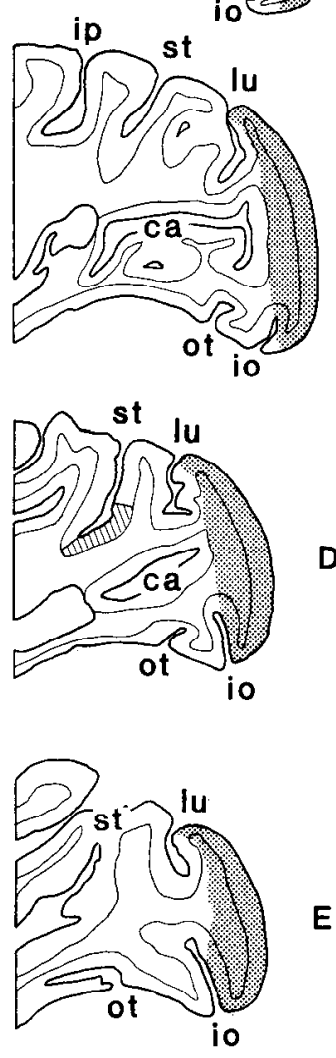

$E$

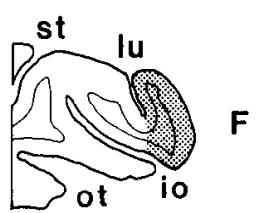

Figure 2. Reconstruction of striate cortex damage in case no. 555 (partial bilateral lesion). Center: Top, Dorsal views of each hemisphere. Far right and left, Parasagittal sections taken from the levels indicated in the dorsal view. Center: Middle, Map of visual field illustrating the lesion zone. Center: Bottom, Parasagittal sections through the LGN from each hemisphere. Other conventions are as for Figure 1.

the lesion zone was intermediate between the distributions for the other 2 categories. The distribution of strong, weak, and no responses for each RF category was significantly different from the normal sample distribution $\left(\chi^{2}, d f=2, p<0.0001, p<\right.$
$0.001, p<0.02$ for cells with RFs completely within, partially within, or outside the striate lesion zone, respectively).

There were no significant overall differences arnong the different lesion cases in the proportions of strong, weak, and absent 
RIGHT

A



B


D

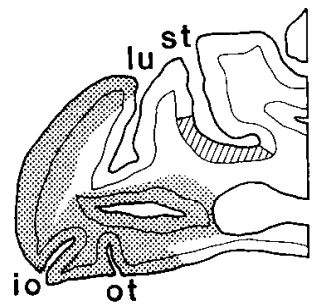

E
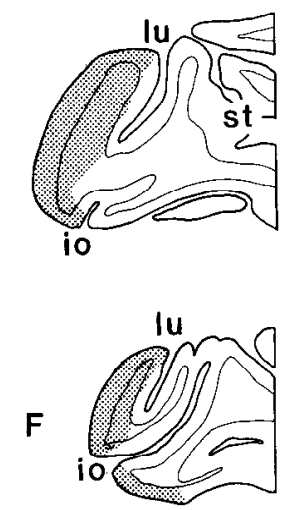

no. 561


LGN

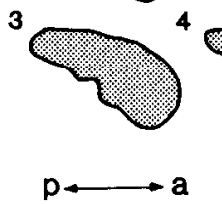

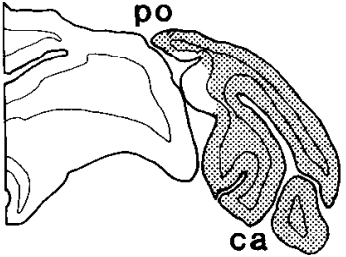

A

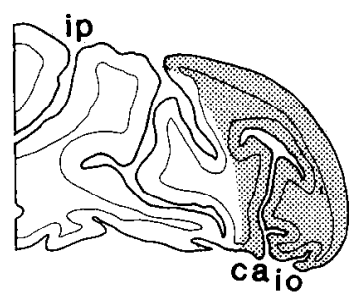

B


Figure 3. Reconstruction of striate cortex damage in case no. 561 (total bilateral lesion). Conventions are as for Figure 2.

responses in the lesion zone $\left(\chi^{2}=6.0, d f=4, p>0.20\right)$. More specifically, there was no difference between the total striate lesion case and the partial cases in the proportions of responsive and unresponsive recording sites $\left(\chi^{2}=6.0 ; d f=1, p>0.30\right)$. The finding of a similar proportion of responsive recording sites in the total bilateral case argues against the supposition that, in the partial cases, responses attributed to the lesion zone might have resulted from inadvertent stimulation of intact striatc inputs by the use of stimuli extending beyond the putative RF.

In the unilateral lesion case, the majority of single and multiunits with RFs bordering or overlapping the vertical meridian ("midline RFs") gave robust, evidently normal responses, even 


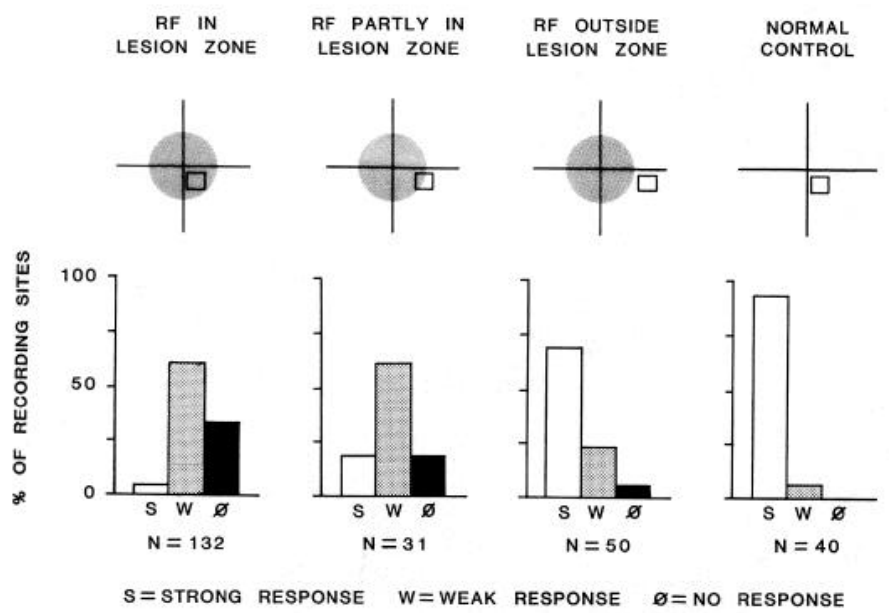

Figure 4. Distributions of responses judged as strong, weak, or absent for MT recording sites with RFs within, partly within, or outside the lesion zone. Data from a sample of single units in normal MT are shown for comparison. In the small schematic above the distribution for each RF category, the axes represent the horizontal and vertical meridians, the shaded area represents the lesion zone, and the small rectangle, RFs of recording sites in that category.

within the lesion zone. To substantiate this impression, we compared the responsiveness of single and multiunits with and without midline RFs for both unilateral and bilateral cases. We defined "midline RFs" as RFs whose borders came within $1^{\circ}$ of the vertical meridian on the contralateral side, overlapped the vertical meridian, or fell within the ipsilateral field. Figure 5 illustrates the incidence of strong, weak, and no responses for single and multiunits with and without midline RFs in the lesion zone. Data from all 3 hemispheres studied in the 2 animals with bilateral lesions have been pooled. The distributions of strong, weak, and no responses were significantly different for recording sites with midline RFs versus those without in the unilateral case $\left(\chi^{2}=20.9, d f=2, p<0.01\right)$ but not the bilateral cases $\left(\chi^{2}\right.$ $=0.4, d f=2, p>0.80)$; this reflects the fact that more cells with midline RFs exhibited strong responses in the unilateral case than in the bilateral cases. Moreover, the distribution of strong, weak, and no responses for recording sites in the unilateral case with RFs away from the midline was very similar to the distributions for those with or without midline RFs in the bilateral cases. Finally, the recording quality on penetrations through the midline representations in this case was notably superior to that in other portions of the lesion zone.

We also studied 39 of the single units that responded to manual testing with the computer-controlled techniques described in detail in Materials and Methods. Of the cells in this sample, 20 had RFs located within the lesion zone, 10 had RFs outside the lesion zone and 9 were from the unilateral case with fields within the lesion zone abutting the vertical meridian. The stimulus for all cells was a bar of light of the length and width judged optimal with hand testing, moving at a speed also judged optimal (see Materials and Methods).

To account for asymmetries in RF dimensions, responses to the moving slit were compensated by considering only the spike rate within a time window determined by the response to the stimulus swept through the RF along its narrowest axis. Responses were measured as the average rate of firing during the time window minus the spontaneous rate and were considered



Figure 5. Distributions of strong, weak, and absent responses for single and multiunits with and without midline RFs for the unilateral case (left) and bilateral cases (right). All had RFs within the lesion zone, with the exception of those single and multiunits from the unilateral case whose RFs extended into the ipsilateral visual field. See also legend to Figure 4.

statistically significant if they exceeded the baseline rate plus (or minus) twice its standard error for the cell in question.

Figures 6 and 7 show examples of data collected with computer-controlled methods from single units with RFs within the lesion zone. None of these cells had fields abutting the vertical meridian from the unilaterally lesioned case. Peristimulus time histograms corresponding to responses to different directions of motion are shown around the bottom of each plot. The location of the cell's RF relative to the lesion zone is shown at the right of each example. Figure 6 illustrates the responses of 2 cells that were characterized as "strong" with manual testing. The cell in Figure $6 \mathrm{~A}$, which was from the partial bilateral case, gave a maximal response of about 18 spikes/sec above baseline rate, which is similar to the average response magnitude (19 spikes/ sec) obtained from cells in normal MT (Albright, 1984). The cell illustrated in Figure $6 B$, which was from the partial unilateral case, gave an even better response (about 35 spikes/sec above baseline rate). Figure 7 illustrates data from 2 single units whose responses were characterized as "weak" with hand testing. Figure $7 A$ shows data from a cell from the animal with the total bilateral lesion; its maximal response was about 5 spikes/ sec above baseline. The cell illustrated in Figure $7 B$, from the partial unilateral case, gave a response of only a few spikes/sec above baseline rate.

For each single unit responding to at least one direction of motion of the automatically presented slit, we calculated a differential response magnitude measure as the algebraic difference between the largest and smallest deviation from baseline (spontaneous activity level) in spikes/sec. By the aforementioned criterion for significance of responses, 34 of the 39 units tested gave measurable responses. For these cells, distributions of the differential response magnitude measure are shown in Figure 8 separately for cells with RFs within the lesion zone, outside the lesion zone, and within the lesion zone but along the vertical meridian in the unilateral case. Data from normal MT (Albright, 1984), obtained under similar conditions, are shown for comparison. Most cells with RFs within the lesion zone had differ- 
A

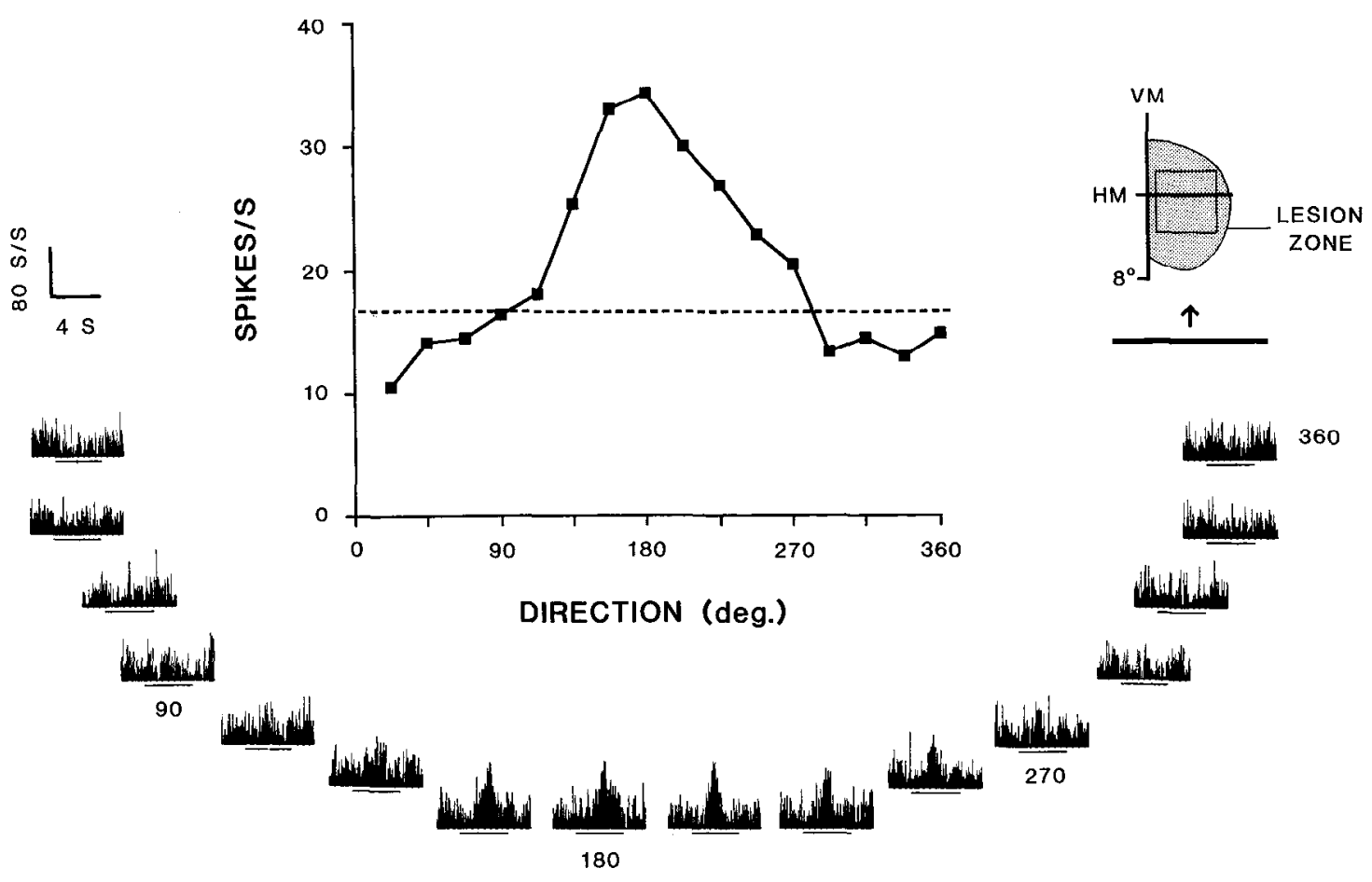

B

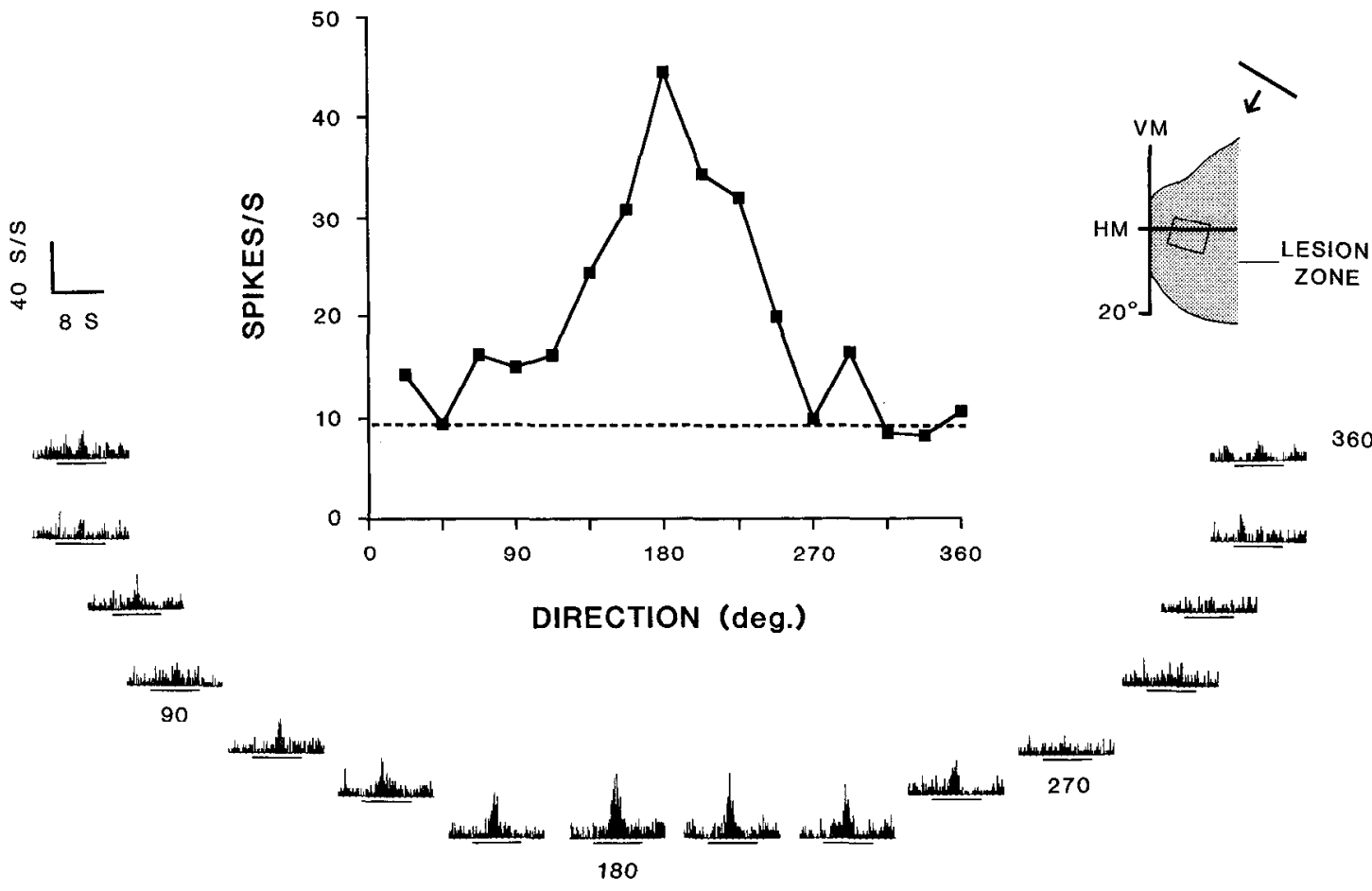

Figure 6. Responses obtained with computer-controlled stimulus presentation from single MT neurons characterized as giving a "strong" response with hand testing. Peristimulus histograms for each direction of stimulus motion are shown in a semicircle around the bottom of the plots of responses (spikes/sec) versus stimulus direction. The RF of each cell relative to the lesion zone is shown in the schematic to the right of each graph; the stimulus used is shown oriented as it was when moving in the preferred direction. Dashed line indicates the rate of spontaneous activity. Direction of stimulus motion has been normalized to $180^{\circ}$ for the preferred direction. $A$. Data from a cell from the partial bilateral case. Stimulus was a $0.5^{\circ} \times 15^{\circ}$ bar of light moving at $8^{\circ} / \mathrm{sec}$. $B$, Data from a cell from the partial unilateral case. Stimulus was a $1^{\circ} \times 15^{\circ}$ bar of light moving at $4 \%$ sec. 
A

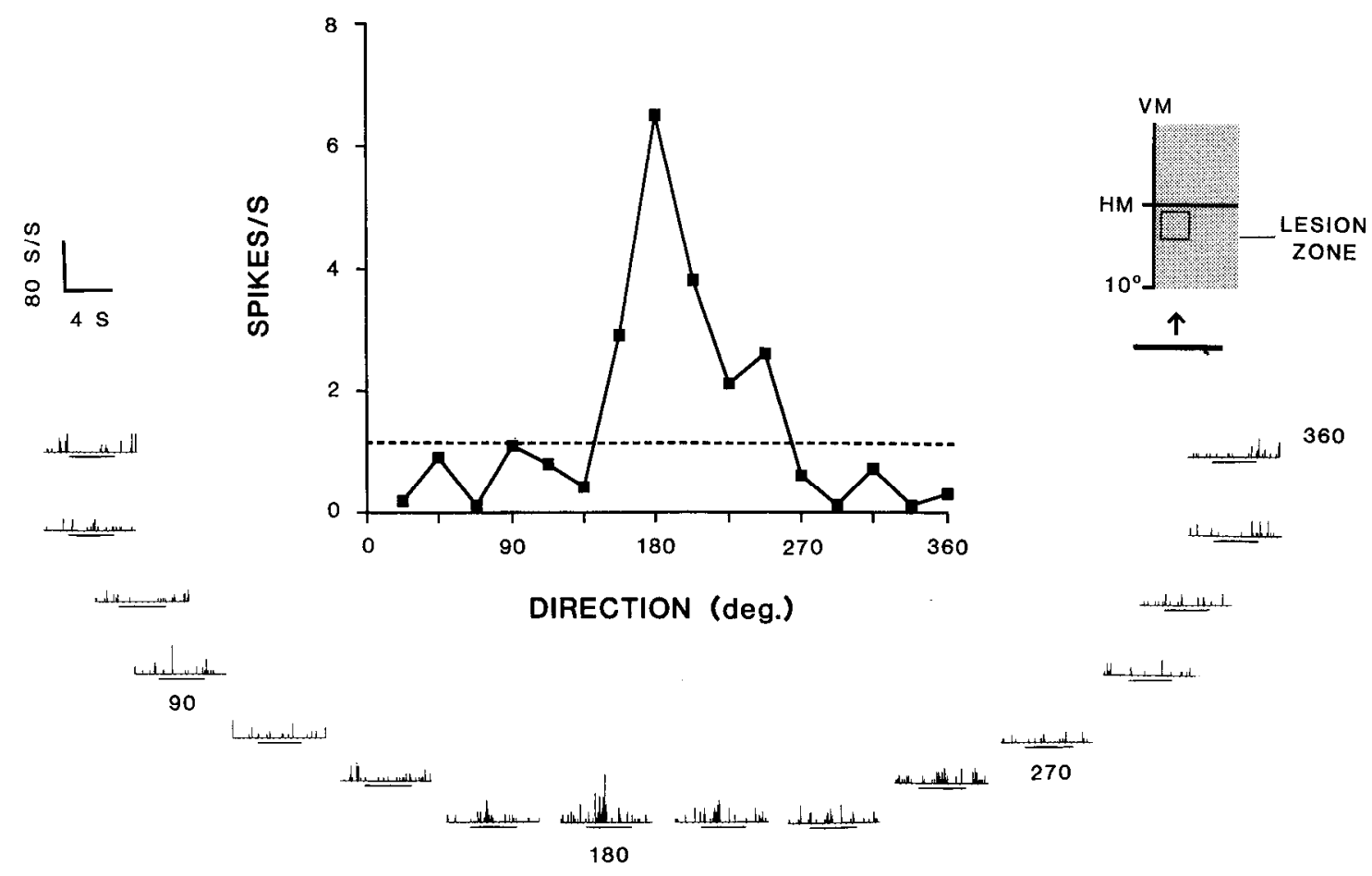

B

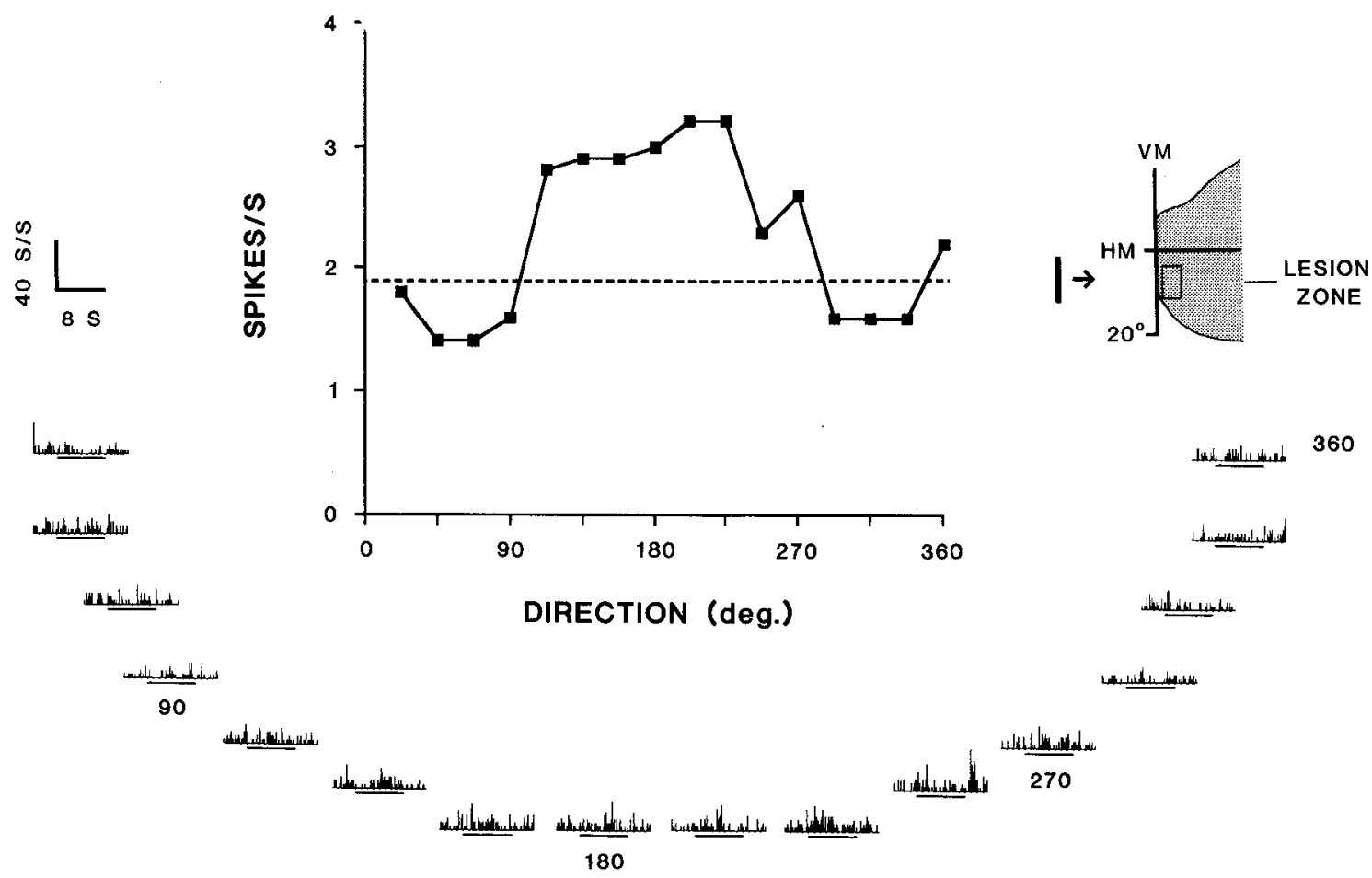

Figure 7. Responses obtained with computer-controlled stimulus presentation from single MT neurons characterized as giving a "weak" response with hand testing. $A$, Data from a cell from the partial unilateral case. Stimulus was a $1^{\circ} \times 10^{\circ}$ bar of light moving at $8 \%$ sec. $B$, Data from a cell from the total bilateral case. Stimulus was a $1^{\circ} \times 10^{\circ}$ bar of light moving at $4 \% \mathrm{scc}$. Scc also legend to Figure 6 . 


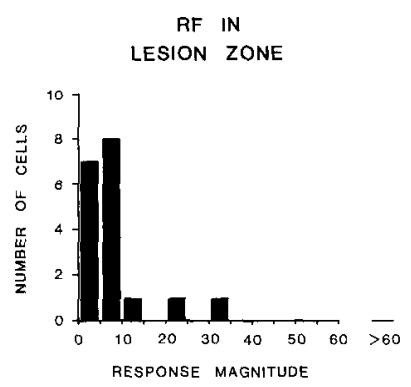

RF
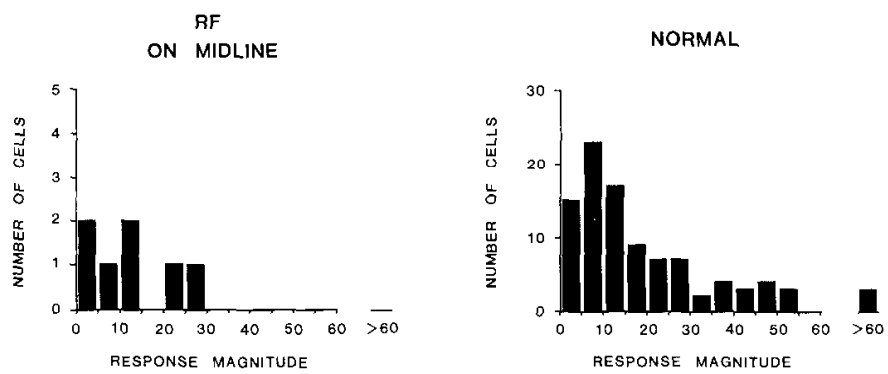

Figure 8. Distributions of differential response magnitude for single units with RFs inside the lesion zone, outside the lesion zone, and within the lesion zone along the midline in the unilateral case. Data from normal MT (replotted from Albright, 1984) are shown for comparison. The stimulus for each cell was a slit of light with dimensions and speed of motion estimated optimal with manual testing. See text for details.

ential response magnitudes under 10 spikes/sec, and there were significantly more low values for this group than for both the normal sample (median test, $\chi^{2}=7.09, p<0.01$ ) and for cells in the lesion cases with RFs outside the lesion zone (median test, $x^{2}=9.23, p<0.01$ ). The distributions of response magnitudes for the other 2 postlesion categories (cells with RFs outside the lesion zone, and within the lesion zone with RFs abutting the vertical meridian from the unilateral case) were not significantly different from the distribution for normal MT.

In addition to evaluating responsiveness in terms of the differential response magnitude measure, we calculated responses as the percentage of baseline firing rate, which can be viewed as a measure of the signal-to-noise ratio of the cell. The distributions obtained by considering this measure were similar to those obtained by considering the differential response magnitude measure. Most cells in the lesion zone had responses of less than 6 times baseline rate, and there were significantly more low values in this group than in the normal sample (median test, $\chi^{2}=4.79, p<0.05$ ). The distributions of values for the other postlesion categories (cells with RFs outside the lesion zone, and from the midline in the unilateral case) were not significantly different from the distribution for units in normal MT. Interestingly, however, no very high values ( $>30$ times baseline) were seen, whereas about $10 \%$ of the normal sample had responses of 30-100 times baseline. The differential response magnitude measure produces a similar picture (Fig. 8).

Although spontaneous activity was burstier in the lesion zone, there were no significant differences between any of the postlesion categories and normal MT in the distributions of spontaneous activity rates.

In summary, the overall responsiveness remaining in MT following striate removal presented a similar picture with either manual or computer-controlled stimulation; while many cells
A

DIRECTION SELECTIVITY

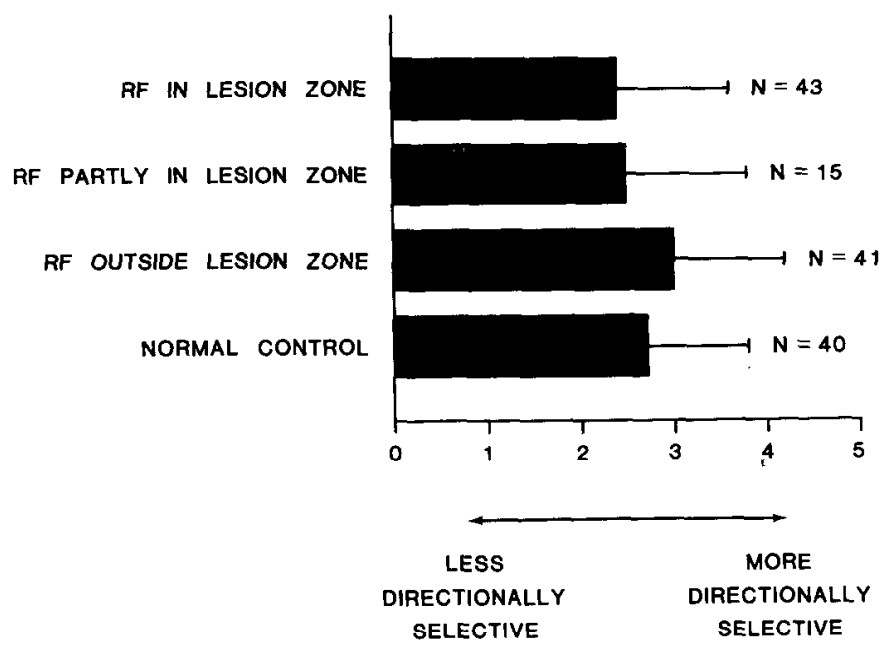

B

DIRECTION TUNING

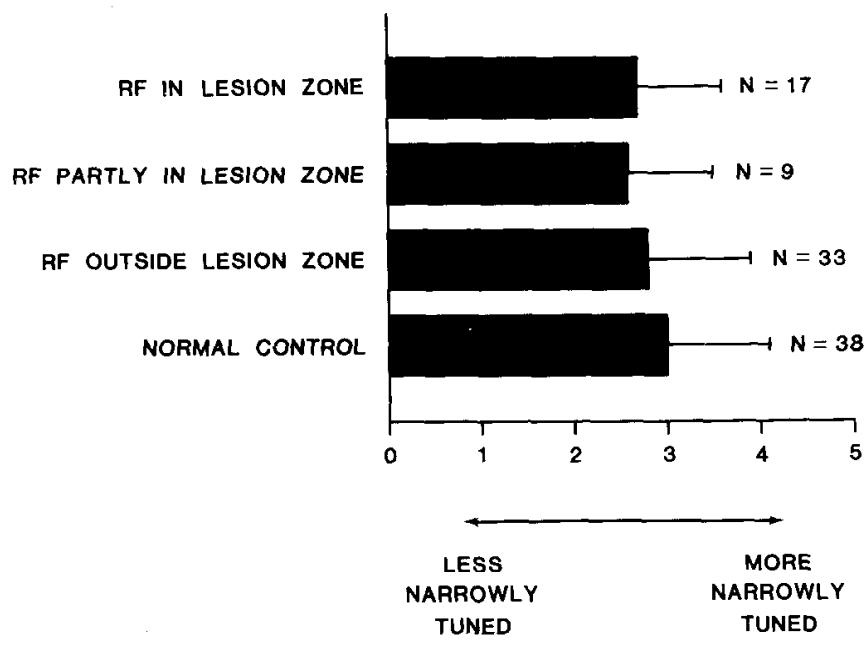

Figure 9. A, Mean ratings of strength of direction selectivity for MT recording sites that retained responsiveness after the striate lesion for each RF category and for cells in normal MT. $B$, Mean ratings of sharpness of direction tuning (tuning bandwidth) for responsive single and multiunits in each RF category and for the normal sample. For both $A$ and $B$, horizontal bars indicate SDs. Rating scales are described in the text.

within the relevant part of the visual field map were still responsive, responses were weaker in the lesion zone than in normal MT except in the midline representation in the unilateral case.

\section{Direction selectivity and direction tuning}

Ninety-nine single and multiunits in MT that remained responsive after the striate lesion were rated for strength of direction selectivity (a measure of the relative response in the preferred and anti-preferred directions) as described in Materials and Methods. Those with RFs along the vertical meridian 


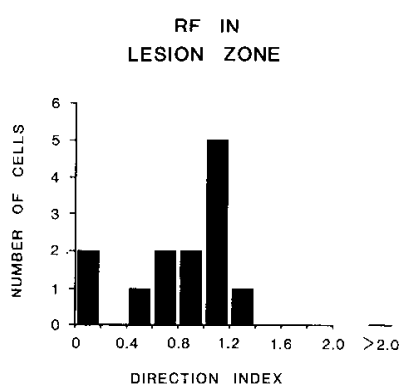

$\mathrm{RF}$

ON MIDLINE

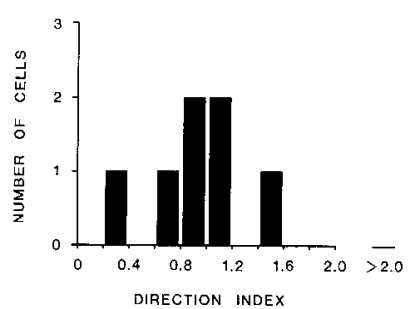

RF OUTSIDE

LESION ZONE

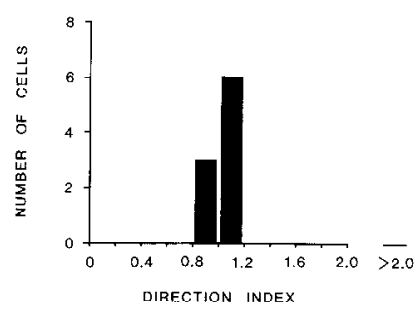

NORMAL

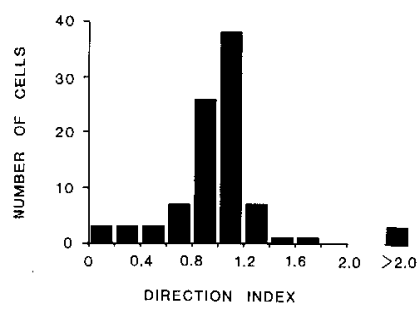

Figure 10. Distributions of direction index values. See also legend to Figure 8. Data from normal MT are replotted from Albright (1984).
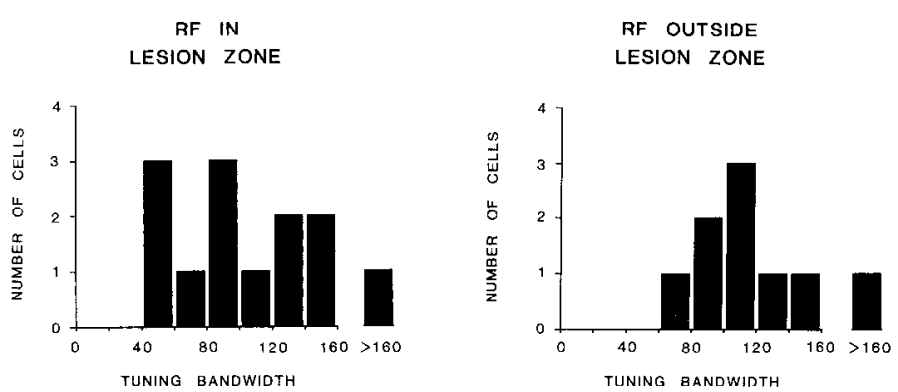

RF

ON MIDLINE

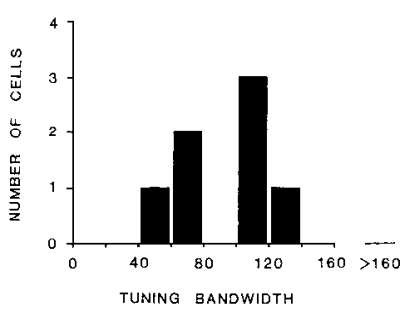

NORMAL

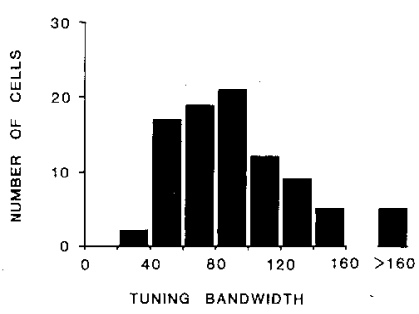

Figure 11. Distributions of tuning bandwidth values. See also legend to Figure 8. Data from normal MT are replotted from Albright (1984).

bandwidth. Several other cells showed direction tuning that was too ragged to be fit with a unimodal tuning curve; such is also the case for a small percentage of neurons found in normal MT. The DI, defined as 1 - (response in anti-preferred direction/ response in preferred direction), is a measure of the relative response to motion in the 2 directions along the axis of motion eliciting the best response. Distributions of this measure are shown in Figure 10 for cells with RFs inside the lesion zone, outside the lesion zone, and within the lesion zone but along the vertical meridian in the unilateral case; data from normal MT (replotted from Albright, 1984) are shown for comparison. For each category, the distribution of direction index values was. clustered around 1.0 and the proportions of cells above and below the median did not differ significantly among any of the groups. The average DI value was also close to 1.0 for all cases, indicating an average tendency for unidirectional tuning with no response in the anti-preferred direction. These findings closely resemble those we obtained with manual testing (cf. Fig. 9A).

Figure 11 shows the distribution of values for tuning bandwidth for each category for cells tested with automatic stimulus presentation. Direction tuning bandwidth, a measure of the sharpness of direction tuning, is defined as the width of the direction tuning curve (a plot of response as a function of direction of motion) at half of its maximum height. The average values of direction tuning bandwidth were similar across categories, and the proportions of cells above and below the median did not differ significantly among the groups.

In order to examine the reliability of our judgments of direction selectivity and direction tuning made with manual testing, we calculated a correlation coefficient between the judgment and the value obtained with automatic stimulus presentation for all single units in our lesion sample that were tested with both methods. Judgments of direction selectivity correlated highly with the direction index value $(r=0.84, n=26)$; likewise, judgments of direction tuning correlated highly with the value of the direction tuning bandwidth $(r=0.79, n=24)$. 

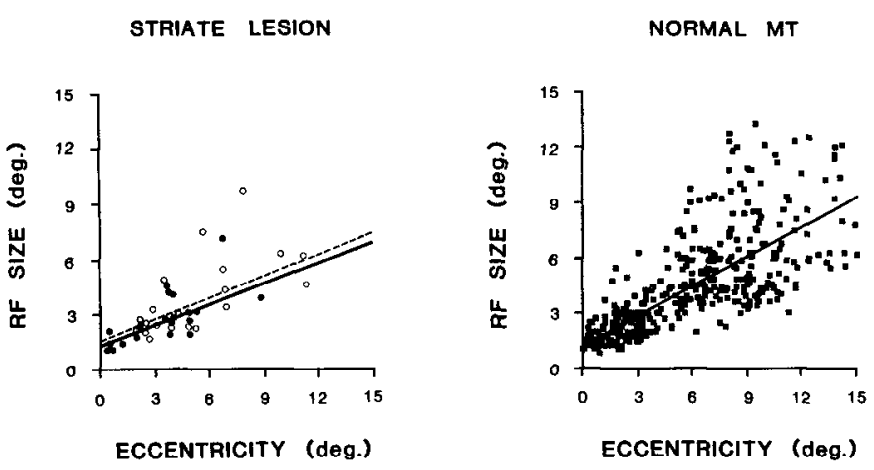

Figure 12. Plots of RF size (square root of RF area) as a function of eccentricity for single units in the animals with striate lesions (left $)$ and in normal MT (right) (replotted from Albright and Desimone, 1987). Straight lines are regression lines fitted to the data by the method of least squares. At left, open circles and the dotted regression line correspond to cells with RFs within the lesion zone, and filled circles and the solid regression line correspond to cells with RFs on the vertical meridian in the unilateral case. Slopes of regression lines: Cells with RFs in lesion zone, 0.40; cells with RFs along the vertical meridian in the unilateral case, 0.35 ; cells in normal MT, 0.59 . Intercepts of regressions: Cells with RFs in lesion zone, 1.53; cells with RFs along the vertical meridian in the unilateral case, 1.34 ; cells in normal MT, 1.17 .

In summary, both manual and computer-controlled testing indicated that direction selectivity and direction tuning bandwidth in MT were not strongly affected by lesions of striate cortex.

\section{Binocularity}

The responses of 40 single and multiunits in the 2 animals with bilateral striate cortex lesions were tested for binocularity and rated according to the scheme employed by Hubel and Wiesel (1962). For most recording sites, strength of response was very similar through the 2 eyes. A few had somewhat better responses through either the contra- or ipsilateral eye, but none were found to be strongly monocular. Direction preference and strength of direction selectivity were usually also very similar through the 2 eyes. These results compare well to published observations on binocularity in normal MT cortex (Maunsell and Van Essen, 1983b; Albright et al., 1984).

\section{Receptive field size and topography}

In normal MT, RF size (defined as the square root of RF area) increases as a linear function of eccentricity whether one considers single units (Albright and Desimone, 1987) or small groups of units (Gattass and Gross, 1981) (but see Maunsell and Van Essen, 1987). We found this relationship to hold after the striate cortex lesion as well. Figure 12 shows plots of RF size versus eccentricity for single cells in MT after the striate cortex lesion (left) and for single cells in normal MT (right) (replotted from Albright and Desimone, 1987). Data from cells with RFs within the lesion zone (open circles, dotted regression line) are shown separately from that for cells with RFs along the vertical meridian in the unilateral case (solid circles and regression line). There were no significant differences among the slopes of the regression equations ( $t$ test for slopes). Likewise, there were no significant differences among the $y$-intercepts ( $t$ test for intercepts). Thus, although responses were generally weaker after the striate lesion and RFs more difficult to plot, RF size (and its variation with eccentricity) does not appear to have been affected in a systematic way.

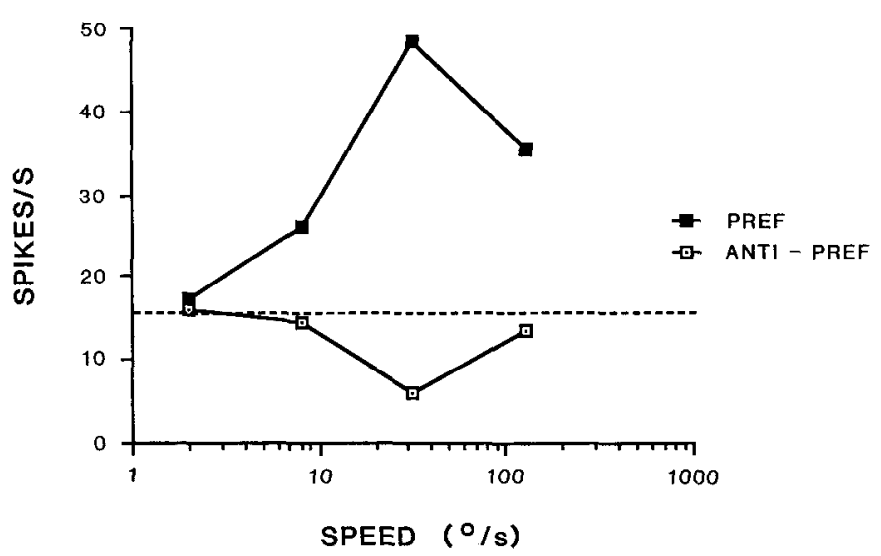

Figure 13. Speed tuning curves for responses to preferred and antipreferred directions of motion for an MT cell with a RF within the lesion zone. Response magnitude is plotted in spikes/sec above baseline. Both the excitatory response to preferred motion and the inhibitory response to anti-preferred motion are greatest at $32 \% \mathrm{sec}$.

In the normal animal, RFs in MT are laid out in an orderly fashion with the fovea represented posterolaterally and the periphery anteriomedially (e.g., Gattass and Gross, 1981; Van Essen et al., 1981). In 3 of the 4 hemispheres used in this study (left hemisphere of no. 542 and both hemispheres of no. 555), we located and mapped out MT prior to the cortical ablation in the course of obtaining normative data for these and other experiments. Following the striate cortex lesion, there was no striking deviation from the normal pattern of topography; in other words, the map of MT obtained prior to the lesion remained a good guide to finding RFs of a given eccentricity, and, in particular, there was no tendency to find more peripheral RFs within the cortex previously devoted to the lesion zone. In the animal with a total bilateral lesion (no. 561) in which we explored MT RFs out to about $15^{\circ}$ eccentricity, there was likewise no marked deviation from the general pattern of topography, i.e., foveal RFs found posterolaterally, and more peripheral RFs anteromedially in the sulcus.

\section{Speed selectivity}

Although we did not extensively test speed selectivity with either manual or computer-controlled methods, it was evident that a given single or multiunit would not always respond with equal vigor to all speeds of stimulus motion. The responses of one single unit to different speeds of stimulus motion are plotted in Figure 13. The cell was from case no. 555 and had a RF contained entirely within the lesion zone. The cell shows clear sensitivity for speed of stimulus motion, with a peak response at around $32 \% \mathrm{sec}$, approximately the modal preferred speed in MT (Maunsell and Van Essen, 1983a; Rodman and Albright, 1987).

\section{Summary of MT properties after striate cortex removal}

In summary, both manual and computer-controlled testing suggest several generalizations regarding visual activity in MT after striate cortex removal. First, considerable visual responsiveness is preserved in MT after striate lesions; however, most of the residual responses are weaker than in the normal animal. When the contralateral striate cortex is intact, MT neurons with midline RFs tend to exhibit normal levels of responsiveness. Moreover, for the single and multiunits that continue to respond following the striate cortex lesion, strength of direction selec- 

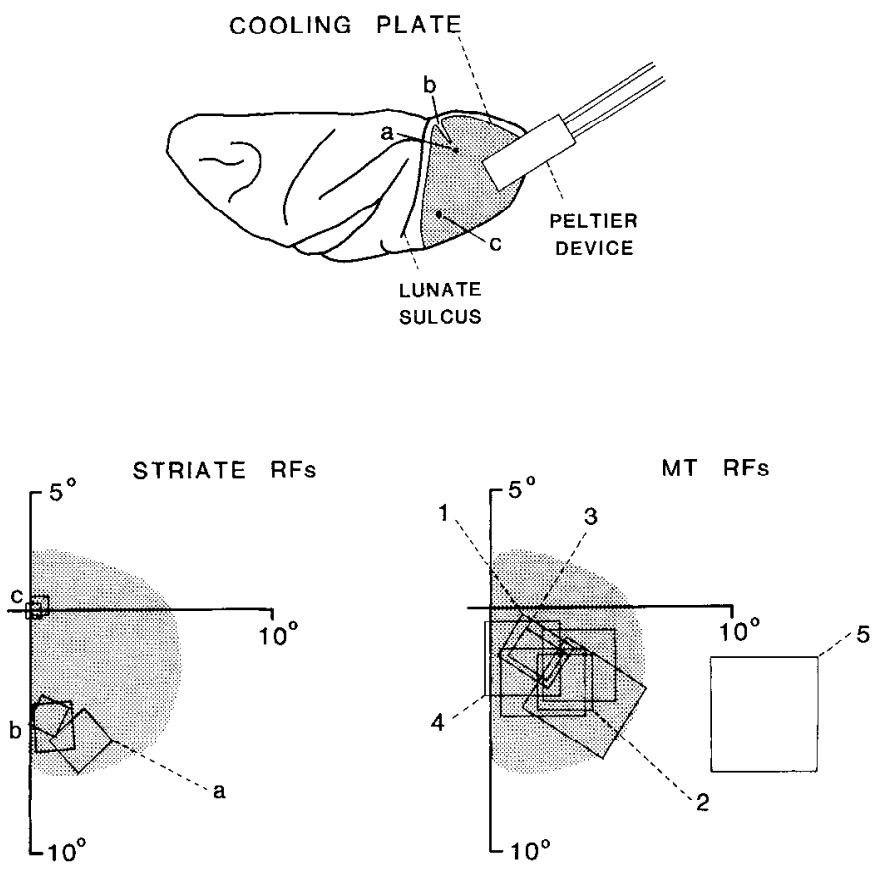

Figure 14. Top, Schematic depiction of placement of cooling plate on the striate cortex. Dura was not actually removed. Holes in the plate for recording cortical temperature and activity are indicated by circles. Some of the sites at which cortical temperature and activity were monitored are indicated by small letters. Bottom left, Portion of visual field representation in striate cortex estimated to be contacted by the cooling plate. Actual RFs recorded under the plate are numbered according to the recording sites shown at top. Bottom right, Locations of RFs recorded in MT relative to the cooled zone in striate cortex. Numbers refer to the RFs of cells specifically discussed in the text.

tivity and sharpness of direction tuning fall within the normal ranges for these parameters. Finally, RF size, overall RF topography, and binocularity are not substantially altered by striate cortex removal.

\section{Effects of Striate Cortex Cooling}

\section{Materials and Methods}

In an additional animal, we reversibly cooled the dorsolateral surface of striate cortex while recording from cells in area MT. This investigation was performed in a terminal recording session lasting approximately 2 d. Prior to this experiment, the animal had been used for other studies, during which area MT was located and mapped. Otherwise, with the modifications described below, preparation for recording, collection and analysis of neural activity, and histological verification of recording sites were the same as for the striate lesion experiments.

Cooling and rewarming of striate cortex was achieved via a silver thermal conduction plate attached to a Peltier cooling device (Cambion Inc., Cambridge, MA). Our procedures were similar to those used previously by Baker and Malpeli (1977) and Schiller and Malpeli (1977) to investigate the effects of reversible inactivation of striate cortex on visually driven activity in the lateral geniculate nucleus and area V2, respectively. With the animal anesthetized and prepared for recording visual responses, a bone opening was madc over the occipital lobc, leaving the dura intact. The cooling plate, which was tapered to fit closely to the convex shape of the exposed dorsolateral striate cortex, was positioned with reference to standard maps of visual topography in striate cortex (Daniel and Whitteridge, 1961; Gattass et al., 1981). We subsequently verified the position of the plate relative to the known topography of striate cortex by recording RFs through several small holes in the plate and around the edge of the plate. Altogether, the plate contacted the representation of approximately $7^{\circ}$ of the lower field and $2^{\circ}-3^{\circ}$ of the upper field. This arrangement is shown schematically at the top of Figure 14. Cooling of striate cortex was accomplished by passing current through the Peltier thermoelectric device. The amount of cooling was proportional to the amount of current passed, which was controlled by a manually operated rheostat and monitored by an ammeter. The tempcraturc of striatc cortex was monitorcd via a thermistor probc (Yellow Springs Instruments) in a 24 gauge needle lowered through one of several small holes in the plate, while cortical activity was monitored via an electrode lowered through another small hole in the plate. Rewarming the cortex was accomplished by passing current in the reverse direction.

After we determined that cooling of the plate did indeed silence activity in striate cortex (see Results), electrode penetrations were made into the part of the visual field representation in MT corresponding to the affected part of striate cortex. Once a single unit in MT was isolated, we plotted its RF and tested it by hand to obtain a rough idea of the optimal speed, direction, and dimensions of a moving bar of light for computer-controlled presentation. Then, the bar of light was presented automatically in 4 directions of motion (both directions along the preferred and orthogonal axes) using methods identical to those described for the striate lesion experiments. After thus establishing a baseline for the cell, striate cortex was cooled from its normal temperature of about $36^{\circ} \mathrm{C}$ and the MT cell retested when striate cortex had equilibrated at a temperature of $5^{\circ}-12^{\circ} \mathrm{C}$. Subsequently, striate cortex was rewarmed to approximately $35^{\circ}-37^{\circ} \mathrm{C}$, and the MT cell tested again. This procedure was repeated for each cell until the effects of cooling were established, or until the cell was lost.

\section{Results}

\section{Effectiveness of cortical cooling}

Throughout the experiment, we monitored the temperature of striate cortex with the thermistor probe inserted $1 \mathrm{~mm}$ into the brain at point $\mathrm{b}$ in Figure 14. Previous studies (Jasper et al., 1970; Baker and Malpeli, 1977) have shown that cortical temperature rises at a fairly constant gradient of $5^{\circ}-7^{\circ} \mathrm{C} / \mathrm{mm}$ as measurements are taken at successive depths from the surface of the cooling probe. Accordingly, we assumed that cortical temperatures were proportionally lower and higher than the measured values above and below the thermistor probe. The transition between the cellular activity of striate cortex and the underlying white matter was recorded at $2.0 \mathrm{~mm}$ below the cortical surface at nearby point a (Fig. 14), so we may estimate that the temperature of the deepest layers of striate cortex was no warmer than about $7^{\circ} \mathrm{C}$ above the value measured by the thermistor. Because the intermediate and deep layers of striate cortex, particularly layers IVB and VI, provide the majority of striate cortex input to MT (Lund et al., 1975; Montero, 1980; Rockland and Pandya, 1981; Maunsell and Van Essen, 1983c), we monitored cortical activity deep in striate cortex $(1.6 \mathrm{~mm}$ below the cortical surface). As striate cortex was cooled, the visually driven and spontaneous activity of both the background and of isolated units recorded at points a-c decreased as the temperature measured at the thermistor fell below $20^{\circ} \mathrm{C}$, and was virtually abolished by $15^{\circ} \mathrm{C}$. Spontaneous activity and responsiveness of striate cortex neurons generally returned quickly upon rewarming. During the course of the experiment, the effectiveness of cooling was repeatedly checked by monitoring activity in striate cortex in this fashion.

\section{Effects of striate cooling on MT neurons}

We recorded from a total of 13 single units that were determined to lie within the myeloarchitectonic borders of area MT upon subsequent histological analysis. Of these, 8 cells were studied with a sufficient number of repetitions of cooling and rewarming to make a conclusive determination of the effect of striate cortex cooling. The RFs of all but one of these cells were contained within the portion of the visual field whose representation in striate cortex was being cooled. 


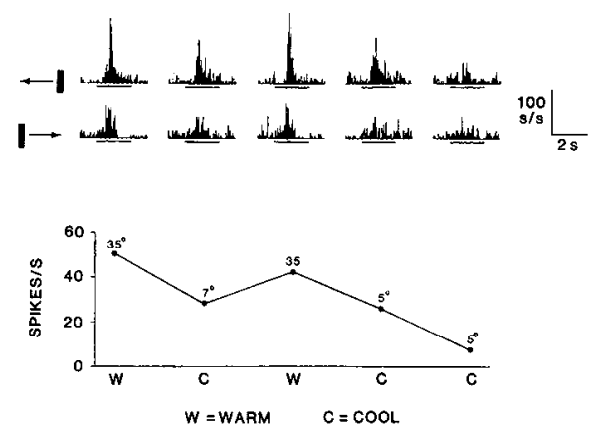

B

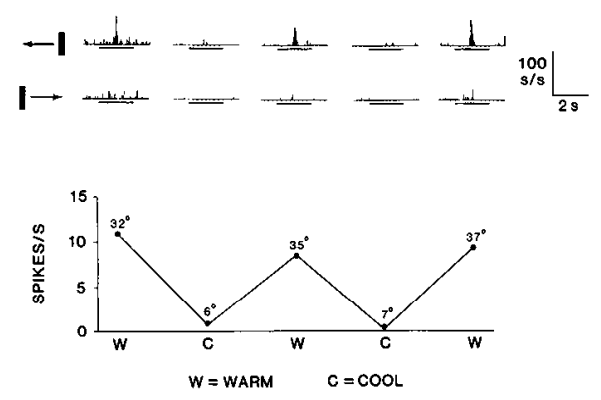

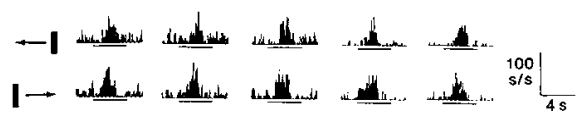

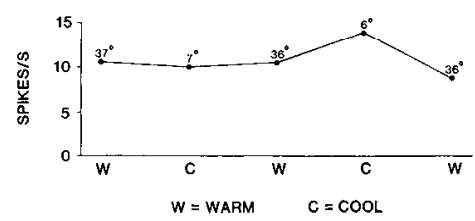

D

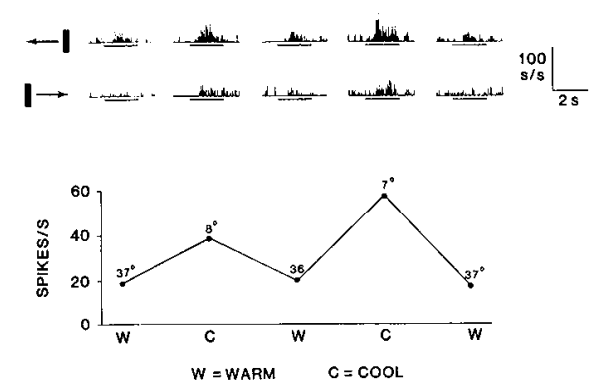

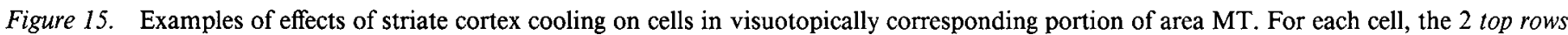

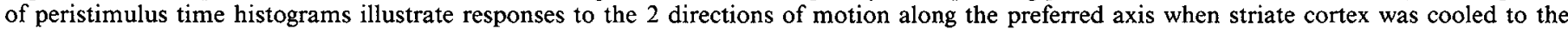

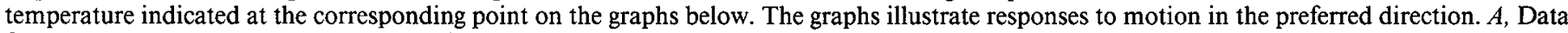

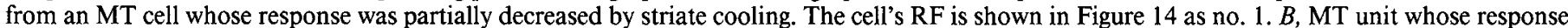

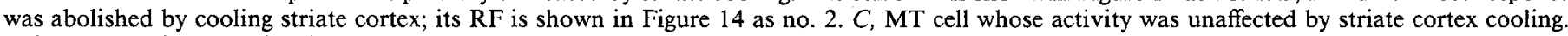
This cell's RF is shown in Figure 14 as no. 3. $D$, MT cell whose activity was elevated by cooling striate cortex (RF no. 4 in Fig. 14).

For 2 MT cells, visual responsiveness was reduced but not abolished by striate cooling. Data from one of these cells are illustrated in Figure 15 $\mathrm{A}$. The cell's RF is labeled in Figure 14 as no. 1. With striate cortex cooled, the cell's response was reduced to a little more than half of what it had been with striate cortex at its normal temperature. When striate cortex was cooled again to $6^{\circ} \mathrm{C}$, the MT cell's response again decreased and then decreased even more as striate cortex was maintained at the lowered temperature $\left(5^{\circ} \mathrm{C}\right)$. The response did not decrease further after holding striate cortex at $5^{\circ} \mathrm{C}$ while the MT cell was tested again. (By the end of the second set of trials taken while striate cortex was at $5^{\circ} \mathrm{C}$, striate cortex had been cooled for approximately $18 \mathrm{~min}$, and we thought it wise to rewarm it again at this point.)

For one MT cell, visual responsiveness and spontaneous activity were nearly abolished by cooling striate cortex (Fig. 15B). This cell's RF is shown in Figure 14 as no. 2. The response (although not the spontaneous activity) recovered promptly upon rewarming.

For 3 MT cells, the visual responsiveness and spontaneous activity were totally unaffected by striate cortex cooling. Data from one cell in this group are shown in Figure $15 C$ (RF no. 3 in Fig. 14). No effect at all on this cell was evident from cooling striate cortex to $6^{\circ}-7^{\circ} \mathrm{C}$, although a check of striate cortex itself confirmed that activity under the plate was abolished at these temperatures.

Finally, the visual responsiveness and spontaneous activity of one MT cell were elevated by striate cortex cooling (Fig. 15D, RF no. 4 in Fig. 14).

For each MT neuron, direction selectivity was assessed before, during, and after striate cortex cooling by comparing responses in the preferred and anti-preferred directions using the directionality index measure defined in the striate lesion section; for no cell that still responded was any systematic effect of cooling seen.

No effect of cortical cooling was observed on the MT cell whose RF lay outside the portion of the visual field representation in striate cortex contacted by the cooling plate (RF no. 5 in Fig. 14).

In summary, the results show, consistent with the effects of striate lesions, that some visually driven activity and direction selectivity remains in MT in the absence of input from striate cortex. Moreover, the cooling results, like the lesion results, indicate that individual MT neurons differ in their dependence on striate cortex.

\section{Discussion}

The present study demonstrates that there is considerable conservation of $\mathrm{MT}$ response properties after removal or inactivation of topographically corresponding portions of striate cortex. The majority of MT neurons retain at least some visual responsiveness following removal or reversible inactivation of striate cortex. Moreover, the remaining responsive cells respond in a directionally selective manner, with strength and sharpness 
of directional tuning distributed comparably to that seen in normal MT. In addition, the binocularity of the responsive cells and the size and overall topographic organization of their RFs are not substantially altered. However, some differences were found in the experimental hemispheres relative to normal MT: About a third of the cells encountered no longer responded to light, the residual responses tended to be weaker than in the normal animal, and the spontaneous activity of some cclls appeared more bursty.

In this section, we will first consider the anatomical basis of the residual responsiveness in MT after removal of striate input. Second, we will discuss the implications of the results for the role of striate cortex in the response properties of MT neurons in the intact animal. Third, we will consider the origins and implications of the direction selectivity observed in MT after the striate removal. Finally, we will consider the findings in light of their significance for the neural basis of the visually guided behavior that survives striate cortex damage in primates.

\section{Afferent basis of residual visual responsiveness in $M T$}

Although MT itself does not receive projections from any portion of the dorsal LGN (e.g., Standage and Benevento, 1981; Maunsell and Van Essen, 1983c), there are weak projections from the interlaminar zones of the LGN to extrastriate areas V4 and possibly V3 (Benevento and Yoshida, 1981; Yoshida and Benevento, 1981; Yukie and Iwai, 1981), both of which project to MT (Maunsell and Van Essen, 1983c; Ungerleider and Desimone, 1986). However, it is not clear whether these minor projections from the interlaminar zones could sustain the level of responsiveness seen in MT after the striate cortex lesion. The very similar levels of responsiveness that we found in MT in the lesion cases with minimal (no. 555) and extensive (no. 561) ventral extrastriate damage also argue against a crucial role for extrastriate cortex posterior to MT in the residual responsiveness after striate removal.

Another possible source of visual input following striate cortex removal might be the "feedback" or "descending" projections from areas such as MST and VIP. MST, at least, is connected with the superior temporal polysensory area (STP), which contains some cells responsive in the hemifield contralateral to a striate lesion (Bruce et al., 1986). However, it seems unlikely that feedback projections from an area such as MST, with its large RFs and very crude topography (Desimone and Ungerleider, 1986), could be responsible for the conservation of RF size and topography in M' devoid of striate input.

Behavioral studies have demonstrated the role of spared portions of peripheral striatc cortex in the visually guided bchaviors that survive striate damage (see Weiskrantz, 1986). Accordingly, one might suppose that the remaining portions of striate cortex in our animals have been largely responsible for the responsiveness seen in the "lesion zone" in MT. This seems unlikely to us for 3 reasons. First of all, this would again presuppose the construction of small, discrete RFs within a topographic representation from dissimilar input (in this case, from striate neurons mapping nonoverlapping portions of the visual world). Second, the similar results obtained in MT for the partial and total striate lesions argue against a crucial role for spared striate cortex. Third, in the partial cases, there was actually a slight diminution of responsiveness in MT outside the lesion zone relative to normal $\mathrm{MT}$, suggesting a possible diminution in peripheral striate function as well.

In addition to the various cortical inputs to MT, there are subcortical routes by which visual information might reach MT. One such route involves the superior colliculus and its thalamic target, the pulvinar. The superficial layers of the superior colliculus receive direct retinal input (Hubel et al., 1975; Pollack and Hickey, 1979) and remain visually responsive following striate cortex removal (Schiller et al., 1974). The lateral and inferior divisions of the pulvinar receive input from the superficial layers of the superior colliculus (Benevento and Fallon, 1975; Harting et al., 1980) and project to MT (Maunsell and Van Essen, 1983c; Ungerleider et al., 1984). Although striate cortex removal severely disrupts neuronal processing in the lateral and inferior divisions of the pulvinar, about $15 \%$ of the cells in both zones remain responsive (Burman et al., 1982; Bender, 1983). In a study subsequent to the present report, we found that destruction of the superior colliculus eliminates the residual responsiveness found in $\mathrm{MT}$ after striate cortex lesions (Rodman et al., 1986).

\section{Contribution of striate cortex to response properties in $M T$}

The present results demonstrate that area MT contains a heterogenous population of neurons with respect to dependence on striate cortex for responsiveness to light. Following the striate lesion, two-thirds of the single and multiunits with RFs within the lesion zone still gave clear responses, although most of these responses were found to be relatively weak. These MT neurons are only partially dependent on the integrity of striate cortex. The remaining one-third within the striate lesion zone were unresponsive; this suggests that striate cortex is essential for their responsiveness in the normal state. The effects of temporary cooling of striate cortex on responsiveness in MT parallel the ablation results: The responses of several neurons were diminished, the responses of several others were unaffected, and the responses of one cell were obliterated. The finding of MT neurons that continue to respond during cooling of striate cortex suggests that the responsiveness seen many weeks after the cortical ablation is due to pathways present in the intact animal and is not primarily a result of a process of recovery or reorganization following the lesion.

Striate cortex removal also appeared to have effects outside the "lesion zone" in MT. After the striate lesion, the distribution of strong, weak, and no responses was significantly different from the normal sample for single and multiunits with RFs outside the lesion zone. Furthermore, it is suggestive that no cells with RFs outside the lesion zone had response magnitudes as high as the highest values found in the normal sample. There are several possible explanations of this effect outside the lesion zone. First, convergent projections from striate cortex to nonretinotopically correspondent portions of MT (Montero, 1980) may, when severed, fail to make their normal contribution to the excitability of cells outside the lesion zone in MT and thus contribute to decreased responsiveness in this region. Similarly, local excitatory connections from cells in the lesion zone to cells beyond it in MT might not function normally and serve to decrease excitability outside the lesion zone. Finally, it is possible that the involvement of adjacent white matter caused the striate lesions to partially affect portions of the visual field representation extending slightly beyond the lesion zone, as defined by examination of direct cortical damage and LGN degeneration.

In addition to contributing to the normal vigor of responses in MT, striate cortex may ultimately be responsible for a contribution from callosal connections to responsiveness along the 
vertical meridian representation in MT. Such a connection is suggested by the finding of a pocket of particularly robust activity within the lesion zone only in the unilateral striate lesion case, and only in the portion of MT representing the midline. Striate cortex, moreover, appears to play some role in the tonic electrical characteristics of M'l neurons; although we observed considerable responsiveness and direction selectivity in MT deprived of striate cortex input, the unusual burstiness of the spontaneous activity of many of the neurons we studied might conceivably render their signals more ambiguous to their targets.

Since MT neurons differ in their degree of dependence on striate cortex, one might expect that MT neurons that derive all their responsiveness from striate cortex (i.e., those which cannot be visually driven following the striate lesion) differ from those cells that are only partly dependent on striate cortex along other dimensions as well. In other words, one might expect to observe the absence of some particular type of selectivity or a marked shift in the distribution of some parameter such as sharpness of direction selectivity or preferred speed. While such a shift was not evident in our measurements of directional characteristics, ocular dominance, or RF size, it is worth pointing out that there are a variety of possible additional characteristics of MT neurons that we did not study and that may be influenced by the striate cortex. For example, we did not study visual response latency or pattern-motion selectivity (Movshon et al., 1985; Rodman and Albright, 1989), which might differ between populations of MT neurons with differential dependence on striate cortex. Similarly, many neurons in normal MT show direction selectivity independent of the cues employed for figure-ground segregation (Albright, 1987); it also remains to be seen whether this property requires striate cortex input.

The contributions to MT responsiveness that originate in striate cortex and that are disturhed hy its removal may depend on direct striate cortex input to $\mathrm{MT}$, on striate input to structures projecting to $\mathrm{MT}$, or on a combination of routes. Responsiveness in area V2, which provides a particularly heavy input to MT (Maunsell and Van Essen, 1983c) is abolished by striate cooling (Schiller and Malpeli, 1977). Either area V2 or area V3 (whose dependence on striate cortex has not yet been addressed) might provide a relay from striate cortex to MT. Alternatively, striate cortex may contribute to responsiveness in MT at least in part via an indirect route through the pulvinar. As mentioned above, the majority of cells in the lateral and inferior pulvinar, regions that project to $\mathrm{MT}$, are dependent on striate cortex for visual responsiveness (Burman et al., 1982; Bender, 1983).

Origin of direction selectivity in $M T$

Striate cortex appears to be unnecessary for the directionally selective properties of many MT neurons. The vast majority of responsive single and multiunits with RFs within the lesion zone gave clearly direction-selective responses with manual testing; mean ratings of direction selectivity and direction tuning for recording sites with RFs in the lesion zone did not differ significantly from those oblained for units with RFs parlly or wholly outside the lesion zone or from the mean for units in normal MT. For cells tested with automatic stimulus presentation, the ranges and distributions of direction index and direction tuning bandwidth values were similar to those found for normal MT. While we cannot exclude the possibility that subtle differences in strength or broadness of tuning might have been missed with our sample of cells examined with computer-controlled methods, it is clear that pronounced direction selectivity remains in
MT after the striate cortex lesion, including highly selective, narrowly tuned responses. These findings are particularly intriguing in view of the far more devastating effects of striate removal on structures such as the pulvinar and $\mathrm{V} 2$, and they strongly suggest that MT contains intrinsic circuitry sufficient to produce directionally selective responses from nonselective input.

As described in the previous section, the residual visual responsiveness in MT after the striate cortex lesion may be dependent on a tectopulvinar route involving the inferior and lateral subdivisions of the pulvinar. Since direction selectivity in these subdivisions is eliminated by striate cortex removal, visual input reaching $\mathrm{MT}$ via such a route would be nonselective as well. These observations are consistent with the model of direction selectivity proposed by Mikami et al. (1986a, b) for MT and applied by Motter et al. (1987) to posterior parietal (PP) cortex. Experiments by both groups of investigators have provided evidence that the generation of direction selectivity in both MT and PP might depend on interactions between nonselective RF subunits larger than those found in the input zones to each region. Thus, it appears that cortical direction selectivity might be generated de novo in at least one region beyond the striate cortex. On the other hand, the antidromic experiments of Movshon and Newsome (1984) suggest that some MT ncurons do receive directionally selective inputs from striate cortex; these MT cells may be those whose responses are obliterated by striate removal.

\section{Possible role of area MT in "blindsight"}

A surprising amount of visually guided behavior survives damage to striate cortex in both humans and monkeys. Prominent among the surviving abilities is a capacity to localize small stationary stimuli either by eye movements or by visually guided reaching or pointing (Poppel et al., 1973; Weiskrantz et al., 1974; Perenin and Jeannerod, 1975; Mohler and Wurtz, 1977; Feinberg et al., 1978; Zihl, 1980; Weiskrantz, 1986). Collectively termed "blindsight" (Weiskrantz et al., 1974), the surviving functions may be summarized as a residual capacity to detect and localize stimuli in the absence of an ability to identify them (see, for example, Humphrey, 1972). Because of these characteristics, because of the unconscious nature of the preserved vision in humans, and because of the dependence of the preserved vision on the superior colliculus and/or pretectum, it has often been assumed that blindsight reflects predominantly subcortical processing (see Campion et al., 1983).

There is an interesting parallel, however, between some of the abilities that characterize blindsight and the persistence of motion-sensitive properties in area MT after striate lesions. For example, monkeys with striate cortex lesions are capable of detecting motion and even discriminating between different angular velocities (Keating, 1980), and apparently blind human patients have also been shown to possess rudimentary information regarding direction and speed of visual motion (Riddoch, 1917; Barbur et al., 1980; Perenin et al., 1980; Tychsen et al., 1988); detection of apparent motion has also been described within a scotoma (Blythe et al., 1986). These abilities, as well as the recovery of visually guided reaching behavior, are presumably dependent upon the activity of directionally selective neurons somewhere in the visual system. Thus far, area MT is the only primate visual structure known to have directionally selective cells in the absence of striate cortex, suggesting 
that MT may have a crucial role in some of the behaviors that comprise the phenomenon of blindsight.

On the other hand, there are behavioral dysfunctions in monkeys after striate lesions that may reflect the lowered gain of the motion signal arising from area MT in a destriated animal. For example, after unilateral striate lesions, monkeys show oculomotor deficits that suggest an inability to use information about the vclocity of a moving target (Segraves et al., 1987). In the intact animal such information is provided at least in part by MT neurons (Newsome et al., 1985; Newsome and Pare, 1986).

\section{References}

Albright, T. D. (1984) Direction and orientation selectivity of neurons in visual area MT of the macaque. J. Neurophysiol. 52: 1106-1130.

Albright, T. D. (1987) Isoluminant motion processing in macaque visual area MT. Soc. Neurosci. Abstr. 13: 1626.

Albright, T. D., and R. Desimone (1987) Local precision of visuotopic organization in the middle temporal area (MT) of the macaque. Exp. Brain Res. 65: 582-592.

Albright, T. D., R. Desimone, and C. G. Gross (1984) Columnar organization of directionally selective cells in visual area MT of the macaque. J. Neurophysiol. 51: 16-31.

Baker, F. H., and J. G. Malpeli (1977) Effects of cryogenic blockade of visual cortex on the responses of lateral geniculate neurons in the monkey. Exp. Brain Res. 29: 433-444.

Barbur, J. L., K. H. Ruddock, and V. A. Waterfield (1980) Human visual responses in the absence of the geniculo-calcarine projection. Brain 102: 905-928.

Bender, D. B. (1983) Visual activation of neurons in the primate pulvinar depends on cortex but not colliculus. Brain Res. 279: 258261.

Benevento, L. A., and J. H. Fallon (1975) The ascending projections of the superior colliculus in the rhesus monkey (Macaca mulatta). J. Comp. Neurol. 160: 339-362.

Benevento, L. A., and G. P. Standage (1983) The organization of projections of the retinorecipient and nonretinorecipient nuclei of the pretectal complex and layers of the superior colliculus to the lateral pulvinar and medial pulvinar in the macaque monkey. J. Comp. Neurol. 271: 307-336.

Benevento, L. A., and K. Yoshida (1981) The afferent and efferent organization of the lateral geniculo-prestriate pathways in the macaque monkey. J. Comp. Neurol. 203: 455-474.

Blythe, I. M., J. M. Bromley, C. Kennard, and K. H. Ruddoch (1986) Visual discrimination of target displacement remains after damage to the striate cortex in humans. Nature 320:619-621.

Bruce, C., R. Desimone, and C. G. Gross (1986) Both striate cortex and the superior colliculus contribute to the visual properties of neurons in the superior temporal polysensory area in the macaque. J. Neurophysiol. 5: 1057-1075.

Burman, D., G. Felsten, and L. Benevento (1982) Visual properties of neurons in the lateral pulvinar of normal and occipital lobectomized macaques. Assoc. Res. Vis. Ophthalmol. Suppl. 22: 237.

Campion, J., R. Latto, and Y. M. Smith (1983) Is blindsight an effect of scattered light, spared cortex and near-threshold vision? Behav. Brain Sci. 6: 423-486.

Cragg, B. G., and A. Ainsworth (1969) The topography of the afferent projections in the circumstriate visual cortex of the monkey studied with the Nauta method. Vision Res. 9: 733-747.

Daniel, P. M., and D. Whitteridge (1961) The representation of the visual field on the cerebral cortex in monkeys. J. Physiol. (Lond.) 159: 203-221.

Desimone, R., and L. G. Ungerleider (1986) Multiple visual areas in the caudal superior temporal sulcus of the macaque. J. Comp. Neurol. 248: 164-189.

Feinberg, T. E., T. Pasik, and P. Pasik (1978) Extrageniculostriate vision in the macaque. VI. Visually guided accurate reaching behavior. Brain Res. 152: 422-428.

Gallyas, F. (1969) Silver staining of myelin by means of physical development. Orvostucomany $20: 433-489$.
Gattass, R., and C. G. Gross (1981) Visual topography of the striate projection zone in the posterior superior temporal sulcus (MT) of the macaque. J. Neurophysiol. 46: 621-638.

Gattass, R., C. G. Gross, and J. H. Sandell (1981) Visual topography of V2 in the macaque. J. Comp. Neurol. 201: 519-539.

Glickstein, M., J. L. Cohen, B. Dixon, A. Gibson, M. Hollins, E. LaBossiere, and F. Robinson (1980) Corticopontine visual projections in macaque monkeys. J. Comp. Neurol, 190: 209-229.

Harting, J. K., M. F. Huerta, A. J. Frankfurter, N. L. Strominger, and G. J. Royce (1980) Ascending pathways from the monkey superior colliculus: An autoradiographic analysis. J. Comp. Neurol. 192: 853882.

Hubel, H., and T. N. Wiesel (1962) Receptive fields, binocular interaction and functional architecture in the cat's visual cortex. J. Physiol (Lond.) 160: 106-154.

Hubel, H., S. LeVay, and T. N. Wiesel (1975) Mode of termination of retinotectal fibers in macaque monkey: An autoradiographic study. Brain Res. 96: 25-40.

Humphrey, N. K. (1972) Seeing and nothingness. New Scientist 53: 682-684.

Jasper, H. H., D. G. Schacter, and J. Montplaiser (1970) The effect of local cooling upon spontaneous and evoked electrical activity of cerebral cortex. Can. J. Physiol. Pharmacol. 48: 640-652.

Keating, G. (1980) Residual spatial vision in the monkey after removal of striate and preoccipital cortex. Brain Res. 187: 271-290.

Lund, J. S., R. D. Lund, A. E. Hendrickson, A. H. Bunt, and A. F. Fuchesi (1975) The origin of efferent pathways from the primary visual cortex, area 17, of the macaque monkey as shown by retrograde transport of horseradish peroxidase. J. Comp. Neurol. 164: 287-305.

Malpeli, J. G., and F. H. Baker (1975) The representation of the visual field in the lateral geniculate nucleus of Macaca mulatta. J. Comp. Neurol. 161: 569-593.

Maunsell, J. H. R., and D. C. Van Essen (1983a) Functional properties of neurons in middle temporal visual area of the macaque monkey. I. Selectivity for stimulus direction, speed and orientation. J. Neurophysiol. 49: 1127-1147.

Maunsell, J. H. R., and D. C. Van Essen (1983b) Functional properties of neurons in middle temporal visual area of the macaque monkey. II. Binocular interactions and sensitivity to binocular disparity. $\mathrm{J}$. Neurophysiol. 49: 1148-1167.

Maunsell, J. H. R., and D. C. Van Essen (1983c) The connections of the middle temporal visual area (MT) and their relationship to a cortical hierarchy in the macaque monkey. J. Neurosci. 3:2563-2586.

Maunsell, J. H. R., and D. C. Van Essen (1987) Topographic organization of the middle temporal visual area in the macaque monkey: Representational biases and the relationship to callosal connections and myeloarchitectonic boundaries. J. Comp. Neurol. 266: 535-555.

Mikami, A., W. T. Newsome, and R. H. Wurtz (1986a) Motion selectivity in macaque visual cortex. I. Mechanisms of direction and speed selectivity in extrastriate area MT. J. Neurophysiol. 55: 13081327.

Mikami, A., W. T. Newsome, and R. H. Wurtz (1986b) Motion selectivity in macaque visual cortex. II. Spatio-temporal range of directional interactions in MT and V1. J. Neurophysiol. 55: 1328-1339.

Mishkin, M. (1966) Visual mechanisms beyond the striate cortex. In Frontiers of Physiological Psychology, R. Russell, ed., Academic, New York.

Mohler, C. W., and R. H. Wurtz (1977) Role of striate cortex and superior colliculus in visual guidance of saccadic eye movements in monkeys. J. Neurophysiol. 40: 74-94.

Montero, V. M. (1980) Patterns of connections from the striate cortex to cortical visual areas in superior temporal sulcus of macaque and middle temporal gyrus of owl monkey. J. Comp. Neurol. 189: 4555.

Motter, B. C., M. A. Steinmetz, C. J. Duffy, and V. B. Mountcastle (1987) Functional properties of parietal visual neurons: Mechanisms of directionality along a single axis. J. Neurosci. 7: 154-176.

Movshon, J. A., and W. T. Newsome (1984) Functional characteristics of striate cortical neurons projecting to MT in the macaque. Soc. Neurosci. Abstr. 10: 933.

Movshon, J. A., E. H. Adelson, M. S. Gizzi, and W. T. Newsome (1985) The analysis of moving visual patterns. In Study Group on Pattern Recognition Mechanisms, C. Chagas, R. Gattass, C. G. Gross, eds., pp. 117-151, Pontifica Academia Scientiarum, Vatican City.

Newsome, W. T., and E. B. Pare (1986) MT lesions impair discrim- 
ination of direction in a stachastic motion display. Soc. Neurosci. Abstr. 12: 1183 .

Newsome, W. T., R. H. Wurtz, M. R. Dursteler, and A. Mikami (1985) The middle temporal visual arca in the macaque monkcy. Deficits in visual motion processing following ibotenic acid lesions in MT. J. Neurosci. 5: 825-840.

Perenin, M. T., and M. Jeannerod (1975) Residual vision in cortically blind hemifields. Neuropsychologia 13: 1-7.

Perenin, M. T., J. Ruel, and H. Hecaen (1980) Residual visual capacities in a case of cortical blindness. Cortex 16:605-612.

Pollack, J. G., and T. L. Hickey (1979) The distribution of retinocollicular axon terminals in rhesus monkey. J. Comp. Neurol. 185: 587-602.

Poppel, E., R. Held, and D. Frost (1973) Residual visual function after brain wounds involving the central pathways in man. Nature 243 . 295-296.

Riddoch, G. (1917) Dissociation of visual perceptions due to occipital injurics with especial reference to appreciation of movement. Brain 40: $15-57$.

Rocha-Miranda, C., D. Bender, C. G. Gross, and M. Mishkin (1975) Visual activation of neurons in inferotemporal cortex depends on striate cortex and the forebrain commissures. J. Neurophysiol. 38: 475-491.

Rockland, K. S., and D. N. Pandya (1981) Cortical connections of the occipital lobe in the rhesus monkey. Interconnections between areas 17,18 and 19 and the superior temporal sulcus. Brain Res. 212:249270.

Rodman, H. R., and T. D. Albright (1987) Coding of visual stimulus velocity in area MT of the macaque. Vis. Res. 27: 2035-2048.

Rodman, H. R., and T. D. Albright (1989) Single-unit analysis of pattern-motion selective properties in the middle temporal visual area (MT). Exp. Brain Res. (in press).

Rodman, H. R., C. G. Gross, and T. D. Albright (1985) Removal of striate cortex does not abolish responsiveness of neurons in visual area MT of the macaque. Soc. Neurosci. Abstr. 11: 1246.

Rodman, H. R., C. G. Gross, and T. D. Albright (1986) Responses of neurons in visual area MT after removal of the superior colliculus. Soc. Neurosci. Abstr. 12: 1369.

Schiller, P. H., and J. G. Malpeli (1977) The effect of striate cortex cooling on area 18 cells in the monkey. Brain Res. 126: 366-369.

Schiller, P. H., M. Stryker, M. Cynader, and N. Berman (1974) Response characteristics of single cells in the monkey superior colliculus following ablation or cooling of visual cortex. J. Neurophysiol. 37: $181-194$
Segraves, M. A., M. E. Goldberg, S. Deng, C. J. Bruce, L. G. Ungerleider, and M. Mishkin (1987) The role of striate cortex in the guidance of eye movements in the monkey. J. Neurosci. 7: 3040-3058.

Siegel, R. M., and R. A. Andersen (1986) Motion perceptual deficits following ibotenic acid lesions of the middle temporal area (MT) in the behaving monkey. Soc. Neurosci. Abstr. 12: 1183.

Standage, G. P., and L. A. Benevento (1981) Lack of dorsal lateral geniculate input to extrastriate cortical area MT and dorsal visual 2 in the macaque monkey. Soc. Neurosci. Abstr. 8: 680.

Tychsen, L., M. Rizzo, R. R. Hurtig, K. W. Stevens, and E. J. Engelken (1988) Visual motion processing in humans after loss of striate cortex. Soc. Neurosci. Abstr. 14: 796.

Ungerleider, L. G., and R. Desimone (1986) Cortical connections of visual area MT in the macaque. J. Comp. Neurol. 248: 190-222.

Ungerleider, L. G, and M. Mishkin (1979) The striate projection zone in the superior temporal sulcus of Macaca mulatta: Location and topographic organization. J. Comp. Neurol. 188: 347-366.

Ungerleider, L. G., R. Desimone, T. W. Galkin, and M. Mishkin (1984) Subcortical projections of area MT in the macaque. J. Comp. Neurol. 223: 368-386.

Van Essen, D. C., and S. M. Zeki (1978) The topographic organization of rhesus monkey prestriate cortex. J. Physiol. (Lond.) 277: 193-226.

Van Essen, D. C., J. H. R. Maunsell, and J. L. Bixby (1981) The middle temporal visual area in the macaque: Myeloarchitecture, connections, functional properties and topographic organization. J. Comp. Neurol. 199: 293-326.

Weiskrantz, L. (1986) Blindsight: A Case Study and Implications, Clarendon, Oxford, UK.

Weiskrantz, L., E. K. Warrington, M. D. Sanders, and J. Marshall (1974) Visual capacity in the hemianopic field following a restricted occipital ablation. Brain 100: 655-700.

Yoshida, K., and L. A. Bencvento (1981) The projection from the dorsal lateral geniculate nucleus of the thalamus to extrastriate visual association cortex in the macaque monkey. Soc. Neurosci. Abstr. 22: 103-108.

Yukie, M., and E. Iwai (1981) Direct projection from dorsal lateral geniculate nucleus to the prestriate cortex in macaque monkey. $\mathrm{J}$. Comp. Neurol. 201: 81-98.

Zeki, S. M. 1974. Functional organization of a visual area in the posterior bank of the superior temporal sulcus of the rhesus monkey. J. Physiol. (Lond.) 236: 546-573.

Zihl, J. (1980) "Blindsight": Improvement of visually guided eye movements by systematic practice in patients with cerebral blindness. Neuropsychologia 18: 71-77. 